\title{
Fifty Years of Atmospheric Boundary-Layer Research at Cabauw Serving Weather, Air Quality and Climate
}

\author{
Fred C. Bosveld ${ }^{1}$ (D) - Peter Baas ${ }^{2}$. Anton C. M. Beljaars ${ }^{3}$. Albert A. M. Holtslag ${ }^{4}$. \\ Jordi Vilà-Guerau de Arellano ${ }^{4}$. Bas J. H. van de Wiel ${ }^{2}$
}

Received: 21 December 2019 / Accepted: 10 June 2020 / Published online: 22 July 2020

(c) The Author(s) 2020

\begin{abstract}
An overview is given of 50-year Cabauw observations and research on the structure and dynamics of the atmospheric boundary layer. It is shown that over time this research site with its 200-m meteorological tower has grown into an atmospheric observatory with a comprehensive observational program encompassing almost all aspects of the atmospheric column including its boundary conditions. This is accomplished by the Cabauw Experimental Site for Atmospheric Research (CESAR) a consortium of research institutes. CESAR plays an important role in the educational programs of the CESAR universities. The current boundary-layer observational program is described in detail, and other parts of the CESAR observational program discussed more briefly. Due to an open data policy the CESAR datasets are used by researchers all over the world. Examples are given of the use of the long time series for model evaluation, satellite validation, and process studies. The role of tall towers is discussed in relation to the development of more and better ground-based remote sensing techniques. CESAR is now incorporated into the Ruisdael observatory, the large-scale atmospheric research infrastructure in the Netherlands. With Ruisdael the embedding of the Dutch atmospheric community in national policy landscape, and in the European atmospheric research infrastructures is assured for the coming decade.
\end{abstract}

Keywords Atmospheric boundary layer - Cabauw atmospheric observatory · Long time records $\cdot$ Remote sensing $\cdot$ Tall towers

\section{Introduction}

At the time of the first issue of Boundary-Layer Meteorology, now 50 years ago, the construction of the 213-m Cabauw meteorological tower in the Netherlands was well underway. The

Fred C. Bosveld

fred.bosveld@knmi.nl

1 Royal Netherlands Meteorological Institute, De Bilt 3731GA, The Netherlands

2 Technical University Delft, Delft 2628CD, The Netherlands

3 European Centre for Medium Range Forecasting, Reading RG2 9AX, UK

4 Wageningen University and Research, Wageningen 6708PB, The Netherlands 
timing of the construction of a tall meteorological tower and the birth of a scientific journal both specifically devoted to the atmospheric boundary layer (ABL) is not a coincidence. The increase of air pollution in the 1950s and 1960s, especially in the Western countries, induced a growing awareness that boundary-layer processes are at the heart of what people experience in daily life. Developing further our understanding of the ABL was therefore of interest from a scientific point of view in the disciplines of weather, air quality, and climate. But also from a policy point of view, since aviation, transport, energy, and construction form essential ingredients of the society. With the recognition over time that the ABL forms the well-discernible interface between the Earth's surface and the free troposphere, ABL research developed into a distinct and fully-fledged research area within meteorology. At the beginning of the 1970s it was very timely that a journal was established specially devoted to ABL studies, as motivated by Munn (1970) in his editor's preface to BLM, and that tall towers were constructed to probe the $\mathrm{ABL}$ in further detail than previously possible.

Traditionally, most synoptic observations are taken in the lowest $10 \mathrm{~m}$ of the atmosphere and are therefore limited to the local scale. Upper-air observations are performed on a regular basis by deploying radiosondes, with the frequency of soundings in general limited to four per day. Tall towers can therefore fill a gap in ABL monitoring by providing a fixed platform on which reliable and continuous observations can be performed. Because higher levels have a larger footprint, tall towers can bridge the gap between local and regional scale. Towers for meteorological observations are constructed to characterize dispersion conditions, in particular at nuclear research and production sites, to characterize land-atmosphere interaction, and to provide measurements for wind-energy research and application. Already in the 1950s, TV towers were used to install meteorological equipment at heights well above the traditional 10-m level (Rijkoort 1961). Disadvantages of using TV towers include the difficulty in maintenance of the instruments, and the interference of the high-power output of electromagnetic radiation with the meteorological sensors. A nice example of TV tower use is the Hamburg 250-m tower in Germany where measurements started in 1963 and have continued till today (Brümmer et al. 2012).

Probing of the ABL with specially designed meteorological towers advanced over the years. A landmark was the construction of the 310-m meteorological tower of Obninsk in Russia already in 1958, and in the early 1960s, the 80-m Vlaardingen tower in the Netherlands was constructed. A publication on this site appeared as the very first paper in Boundary-Layer Meteorology (Rijkoort et al. 1970). The Vlaardingen tower was the predecessor of the 213-m Cabauw tower, the Netherlands, which was constructed in 1972, the Karlsruhe 200-m tower was also constructed in 1972 (Kohler et al. 2018), followed by the Tsukuba 213-m tower, Japan, in 1975 (Horiguchi et al. 2012) and the 300-m Boulder Atmospheric Observatory, USA, in 1978 (Wolfe and Lataitis 2018). Later towers include the Lindenberg 100-m tower of the German Weather Service in 1998 (Neisser et al. 2002), the Boseong 300-m tower in South Korea and the Beijing 325-m tower (see Qing-Yao et al. 2017), the 300-m tower of the Amazon Tall Tower Observatory (Andreae et al. 2015), and the 304-m tower of the Zotino Tall Tower Observatory in Central Siberia (Winderlich et al. 2010). The Atmospheric Radiation Measurement sites in Oklahoma and north Alaska (USA) operate comprehensive surface stations with lower masts of which the tallest is $60 \mathrm{~m}$ high, and modern ground-based remote sensing instruments (Sisterson et al. 2016). Other shorter masts include the 10-m tower in Valladolid, Spain (Viana et al. 2012), the 48-m Sodankylä tower in Finland (Kangas et al. 2016), and the 102-m Norunda tower in Sweden (Lundin et al. 1999).

Measurements from meteorological towers can be valuable in their own right. However, much more can be learned when the observational program includes also other ABL-related parameters. As the ABL is bounded and influenced from below, observations of surface 
radiation components and surface heat fluxes are a crucial addition to understanding the interactions between land and atmosphere. At the upper side, a characterization of the interface with the free troposphere is of great interest. We refer to sites with such an extended observational program as ABL sites. Each ABL site in the world has its own specific design depending on the interest and expertise of the research groups that are connected to the site. Moreover, such sites can become even more valuable when the ABL observations are part of an even larger observational program. This occurs nowadays due to the advent of remote sensing instruments with which observations of wind, clouds, aerosols, and air quality can be performed at increasing height and dimensionality. We refer to these sites as atmospheric observatories. The Meteorological Observatory Lindenberg of the German Weather Service is such an observatory, where one of the specializations is on surface heterogeneity (Beyrich and Mengelkamp 2006). The Oklahoma ARM observatory combines a large horizontal scale with state-of-the-art remote sensing instruments with a focus on cloud-radiation-aerosol interaction (Sisterson et al. 2016).

The concept of the ABL has proven to be very useful in atmospheric sciences. The structure of the ABL varies widely, depending on the interactions with the surface and the free troposphere aloft, all depending on the character of the surface, the latitude (Coriolis parameter), and cloud conditions (Holtslag and Duynkerke 1998). Experiments at an atmospheric observatory are quite different from laboratory experiments. Many processes interact with each other and these processes cannot be controlled. In the early days of ABL research, field campaigns of days to weeks were performed with a specific research question. It was anticipated that a number of so-called golden days could be selected that met the requirements of the research goal. Nowadays, the alternative is to perform long-term monitoring campaigns in order to be able to select cases that fulfil certain requirements (stable boundary layers or fog, for example), and subsequently analyze within this subset of observations relations between processes and state variables. The longer the time series the more cases will be available in the subset, and the better process relations can be determined. Long-term monitoring also allows for the study of seasonal cycles, inter-annual variability and the "all-weather" process verification of weather, climate and atmospheric composition models. Of interest here is the recent development of so-called testbeds that combine fine-scale simulations with comprehensive observations (Neggers et al. 2012; Gustafson et al. 2019).

The present article gives an overview of 50 years of Cabauw ABL observations and research. Emphasis will be on the last 25 years, since the first 25 years were reviewed by van Ulden and Wieringa (1996) on the occasion of the 25th anniversary of BoundaryLayer Meteorology and the step-down of its first Editor R.E. (Ted) Munn. As such, it may serve as a reference for future ABL studies that use Cabauw observations. Extensive use is made of the report "In higher Spheres" which was published by the Royal Netherlands Meteorological Institute (KNMI) on the occasion of Cabauw's 40th anniversary (Monna and Bosveld 2012). Section 2 describes the organisation of the Cabauw observatory, and the current ABL observational program is described in Sect. 3. A selection of studies that have been performed with observations from Cabauw is presented in Sect. 4 as far as they are related to the structure and dynamics of the ABL. Section 5 discusses the future of atmospheric observatories including the role of tall towers where remote sensing instruments are becoming increasingly prominent.

As mentioned above, we recognize that the ABL interacts with many other aspects of the atmosphere. Clouds and aerosols modulate the surface energy budget, boundary-layer clouds modulate turbulence characteristics of the $\mathrm{ABL}$, aerosols influence fog formation, and $\mathrm{CO}_{2}$ can be used as a tracer for mesoscale circulations, and, on longer time scales, may have a profound influence on ABL processes. However, our focus is on the physical and dynamical 
aspects of the ABL. Although many other aspects are also of interest at Cabauw we shall only briefly touch on them here.

\section{Organisation}

From the start, the responsibility for the Cabauw facility has been at KNMI. Around 1996 the Cabauw observational program needed a major overhaul as instruments and data infrastructure had become obsolete, and a new measurement program commenced in 2000. Meanwhile, international research showed an increasing demand for more detailed information on the atmosphere for the development of weather, climate and air-quality models. In addition, monitoring of essential climate variables, as defined by the World Meteorological Organisation (WMO), became necessary. The development of new measurement techniques and methods enabled observation of an increasingly wider field of atmospheric properties. It became clear that this broad range of observations, requiring all sorts of expertise, could neither be carried out nor interpreted by one single institute. Emerging from existing projects, and based on cooperation between institutes with complementary expertise, the CESAR consortium (Cabauw Experimental Site for Atmospheric Research, http://www.cesar-observatory. nl) was established in 2002. The CESAR Consortium consists of eight research institutes: The KNMI, the National Institute for Public Health and the Environment, the Netherlands Energy Research Centre, the Netherlands Organization for Applied Scientific Research, the Universities of Delft, Wageningen and Utrecht, and the European Space Agency. The goals of CESAR are: (1) Monitoring of long-term trends of climate variables in the atmosphere; (2) Validation of satellite observations and retrieval products; (3) Studies of processes in the atmosphere and at the land surface for the improvement of weather, air quality, and climate models; (4) Evaluation of weather, air quality, and climate models; (5) The development, implementation and validation of new observational methods; and (6) Education of young researchers at the Masters, Doctoral, and post-doctoral levels.

All relevant atmospheric observations carried out by these institutes were concentrated at the Cabauw site. Stimulated by the Dutch national program Climate for Space, and building on earlier forms of international cooperation in European Cooperation in Science and Technology actions, CESAR developed into an internationally front ranking atmospheric observatory for the study of the atmospheric column and its interaction with the land surface. The 213-m mast is still the eye-catching feature at the site (see Fig. 1), but throughout the years observations with surface-based remote sensing instruments became also key elements in the measurement program.

CESAR is part of a number of international networks; CESAR data are included in major international databases, and are used by a large number of researchers throughout the world (see examples below). This is in line with the long-standing KNMI tradition of making Cabauw data freely available for research.

\section{Observations}

\subsection{Introduction}

The Cabauw site is located in the western part of the Netherlands $\left(51.971^{\circ} \mathrm{N}, 4.927^{\circ} \mathrm{E}\right)$. It has a marine west coast climate, $\mathrm{Cfb}$ according to the Köppen climate classification. The site is 


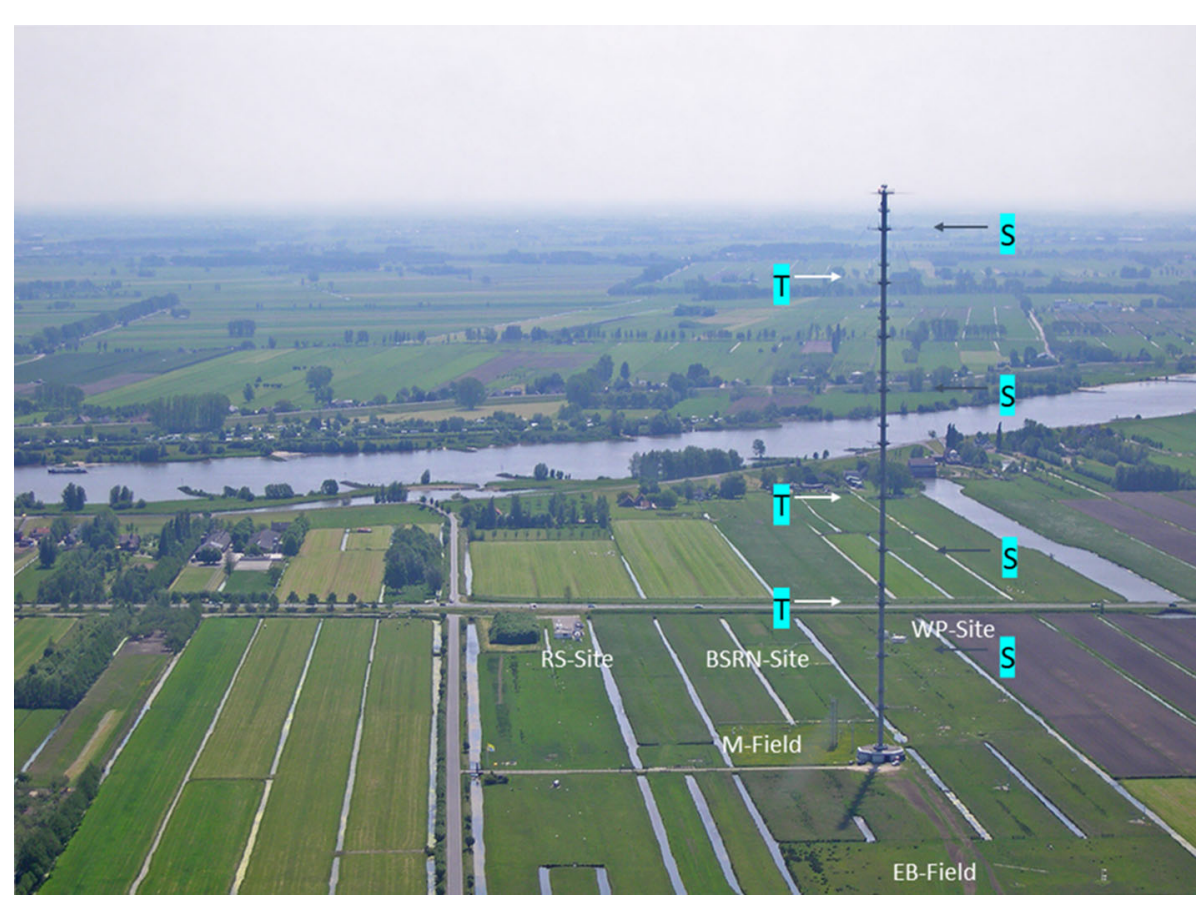

Fig. 1 View to the south of the Cabauw site with the 213-m meteorological tower in a river landscape with managed water table. Indicated are the various observational paddocks. Remote sensing (RS-site), wind profiler (WP-site), baseline surface radiation (BSRN-site), Meteo (M-field), and energy balance (EB-field). Also indicated are the tower levels for turbulence $(\mathrm{T})$ and standard meteorological observations (S). (Photo by Wouter Knap)

located between the main industrial areas of Rotterdam, Antwerp, and Ruhr area at distances between 50 and $100 \mathrm{~km}$. Air quality is very variable at the site, depending on wind direction.

The first years of the Cabauw site were devoted to the development of new measurement and data techniques. This resulted in two periods with continuous observations (1973 and March 1977-February 1979) as described by Wessels (1984). In the same period, several shorter experiments were done to characterize the site and the turbulent structure of the ABL. Results from this first period are described in Van Ulden and Wieringa (1996). Subsequently, an 11-year continuous measurement program (1986-1996) on atmospheric profiles, surface radiation, and surface energy was operated, and is described by Van Ulden and Wieringa (1996) and in more detail in Beljaars and Bosveld (1997). In 1997 the 11year continuous measurement program was discontinued, since the data infrastructure had become old-fashioned and difficult to maintain. The same holds for the instruments of which many had been developed in-house before or around the start of the Cabauw site with the special purpose of measuring accurately the vertical differences over the depth of the $200 \mathrm{~m}$ tower of the main meteorological parameters wind, temperature, and humidity. In the meantime, important developments had taken place in instrumentation and data infrastructure of the meteorological network of the Netherlands. These developments resulted in a reliable network with respect to quality and availability of data on the one hand, and cost-effective maintenance on the other hand. For the current measurement program at Cabauw, starting 
in 2000, use was made of these developments wherever possible. The period 1996-2000 has been bridged by an automatic weather station at the site.

\subsection{Infrastructure}

The infrastructure consists of the main tower, a number of smaller masts and a number of paddocks that are prepared for specific types of observations. Smaller masts are positioned on two sides of the main tower to perform undisturbed wind measurements at 10 and $20 \mathrm{~m}$ height. In Fig. 1 the paddocks are indicated, and includes; the RS-site where the remote sensing instruments are positioned; the BSRN-site where high accuracy radiation observations are performed as part of the Baseline Surface Radiation network (Driemel et al. 2018); the WP-site where the Wind Profiler is located; the M-field where standard meteorological observations are performed including the automatic weather station from the national meteorological network; and the EB-field where energy balance observations are performed.

\subsection{Terrain}

The soil and surface characteristics of the site are described in Van Ulden and Wieringa (1996), Beljaars and Bosveld (1997), and Verkaik and Holtslag (2007). Since then, significant changes within a distance of $5 \mathrm{~km}$ from the Cabauw site have been only in the already disturbed east sector. They include the gradual expansion of the village of Lopik in the direction of the site during the period 2000-2010, and the placement of three wind turbines at $3 \mathrm{~km}$ distance in 2007. Predrag et al. (2018) show a slight inhomogeneity of the 200-m wind speed over time which is likely related to the expansion over time of Lopik.

\subsection{ABL-Related Observations}

Here the instruments are described that relate to the physical aspects of the atmospheric boundary layer. Only the current observational program is described. For changes in instrumentation since 2000, and further details on the measurements we refer to Bosveld (2020).

\subsubsection{The Meteorological Network and Geostrophic Wind}

The meteorological network of The Netherlands consists of 48 automatic weather stations at typical spacing of $50 \mathrm{~km}$, including platforms in the North Sea. Of particular interest are the four neighbouring synoptic stations Schiphol (6240), De Bilt (6260), Zestienhoven (6344), and Gilze Rijen (6350). At De Bilt, $23 \mathrm{~km}$ north-east of Cabauw, radio-soundings are launched once a day at 0000 UTC.

The surface geostrophic wind velocity for Cabauw is derived from pressure observations of the meteorological network (Bosveld et al. 2014a), with pressure readings reduced to mean sea level. Because the surface elevation of the stations involved, relative to mean sea level, is very small this reduction to one horizontal plane can be done very accurately. The accuracy in the estimated sea surface pressure is $0.1 \mathrm{hPa}$, and in the estimated geostrophic velocity components is $0.4 \mathrm{~m} \mathrm{~s}^{-1}$. 


\subsubsection{Soil Heat and Water}

Soil heat flux is measured at the EB-field by a combination of self-calibrating soil heat-flux plates (Hukseflux HFPSC01) and soil temperature sensors (KNMI). Three pairs of soil heatflux plates at 0.05 and $0.10 \mathrm{~m}$ depth are placed on the vertices of a triangle with a base of $2 \mathrm{~m}$. Soil temperature gradients at the top of the upper-soil layer are derived from soil temperature sensors at 0.00 and $0.02 \mathrm{~m}$ depth. The surface soil heat flux is estimated from this combination of observations with high temporal resolution by a method described by De Bruin and Holtslag (1982). In addition, soil temperatures are measured at the same location at nine depths down to $0.5 \mathrm{~m}$. These sensors and its datalogging have a high accuracy and stability. This allows for an independent calorimetric method to estimate surface soil heat flux at a time resolution of 10 min provided that soil heat capacity is known.

The ground water level is measured at four positions with various distances from a ditch, three of them at the M-field and one at the EB-field. The measurements are performed in a tube by means of pressure sensors (Keller 26W); also measured is the water level in the ditch. The ground water sensors are positioned in clay-on-peat soil which may result in gradual changes in depths; the absolute height of the sensors is verified each second year.

Soil water content is measured at the EB-field at five depths down to $0.5 \mathrm{~m}$ with time-domain reflectometry sensors (TRIME-PICO). During the period 2003-2010 a more extensive hydrological observation program was run with measurement of inflow and outflow of the small polder catchment (Brauer et al. 2014).

\subsubsection{Wind, Temperature and Humidity Profiles}

Wind speed and direction is measured with a cup-anemometer and a vane combination (KNMI); special precautions are made to avoid flow interference of the vane on the cup anemometer. The cup anemometer has a response distance of $2.9 \mathrm{~m}$. Wind observations at each level are taken at two (wind speed) or three (wind direction) booms. The best-exposed boom is selected and a correction is made for the remaining flow obstructions by the mast and the boom (Wessels 1983). Temperature is measured with Pt500 elements (KNMI) placed in unventilated screens (KNMI) to avoid the influence of radiation and precipitation. Humidity is measured with polymer-based relative humidity sensors (EplusE 33) placed in unventilated screens separate from the temperature screens. The polymer sensors are heated to decrease measurement problems during humid conditions. Measurement heights are 10, 20, 40, 80, 140 , and $200 \mathrm{~m}$. Additionally, temperature and humidity are measured at 1.5-m height, and temperature also at $0.1-\mathrm{m}$ height.

These instruments have the same calibration cycle as is used in the meteorological network, except for the humidity sensors. They are calibrated and adjusted each 3 months in order to obtain a better accuracy. The latter is necessary to satisfy the requirements for vertical profiling in the lowest $200 \mathrm{~m}$.

\subsubsection{Radiation}

Net radiation can be measured with a single instrument (the so-called net radiometer) or by measuring the sum of the four components: incoming and outgoing longwave and shortwave radiation. Single-instrument net radiometers suffer from design compromises to account for both longwave and shortwave radiation (Halldin and Lindroth 1992; Kohsiek et al. 2007). With the advent of more accurate radiation instruments for longwave and shortwave, as 
implemented in the GEWEX Baseline surface radiation network (BSRN) (Driemel et al. 2018), it has become clear that, currently, the sum-of-component approach is the preferred method, given that high-quality pyranometers and pyrgeometers are used. At Cabauw a BSRN station has been operated since 2005 (Wang et al. 2009). At the EB-field the same type of instruments are employed, namely Kipp and Zonen CM22 pyranometers and Kipp and Zonen CG4 pyrgeometers.

\subsubsection{Surface Fluxes}

The long data record of the surface fluxes of momentum, sensible heat, and latent heat, as started in 1986, is derived from aerodynamic methods based on 10-m wind observations, an assumed roughness length, vertical temperature gradients, net radiation, and surface soil heat flux. Latent heat flux is derived as the residual in the surface energy budget (SEB). These observations are still operational with slight modifications over time, but additionally eddy-correlation (EC) observations have been made since 1995.

A sonic anemometer (Gill-R50) is combined with an open-path $\mathrm{H}_{2} \mathrm{O} / \mathrm{CO}_{2}$ sensor (LICOR7500) at 3-m height at the EB-field. From these measurements, turbulent fluxes of momentum, sensible heat, latent heat, and $\mathrm{CO}_{2}$ are derived following the $\mathrm{EC}$ method, taking into account the necessary corrections (Lee et al. 2004).

With this combination of surface radiative- and heat-flux observations the SEB can be studied, particularly the SEB imbalance, which is a feature found at many sites around the world (Foken 2008), and the Cabauw site is no exception (De Roode et al. 2010). Until this problem is solved, we intend to run the old SEB residual method for estimating latent heat in parallel to the EC observations.

\subsubsection{Profiles and Boundary-Layer Height}

Since 1994 a 1290-MHz boundary-layer wind profiler/RASS (Radian Corporation LAP3000) has been operated (Klein Baltink 1998), which provides profiles of mean horizontal wind velocity, vertical wind variances and backscatter intensity. From the latter component, the convective boundary-layer height is estimated when applicable. By combining tower observations and wind-profiler observations the structure and height of the nocturnal boundary layer can be assessed. A ceilometer (Lufft CHM15k) is operated at the site, with cloud-base height and backscatter profiles archived. From the latter an alternative estimate of the boundary-layer height is derived based on the mixing of aerosols in the ABL.

\subsubsection{Regional Scale Fluxes}

In order to study the representativity of the local flux observations, and the related problem of SEB imbalance, a regional-scale flux program was set-up. A semi-operational program of EC observations at three levels $(60,100,180 \mathrm{~m}$ ) in the tower is run (see Fig. 2), providing the vertical turbulent fluxes of momentum, sensible heat, latent heat, and $\mathrm{CO}_{2}$. An extra-large scintillometer (Kipp and Zonen XLAS) is operated over a 10-km path between the TV tower of IJsselstein and the Cabauw mast at 40-m and later 60-m height (Kohsiek et al. 2002). This technique provides estimates of the average sensible heat flux along the path; for the relation of the XLAS estimates with the sensible heat flux at the surface, see Braam et al. (2012). 


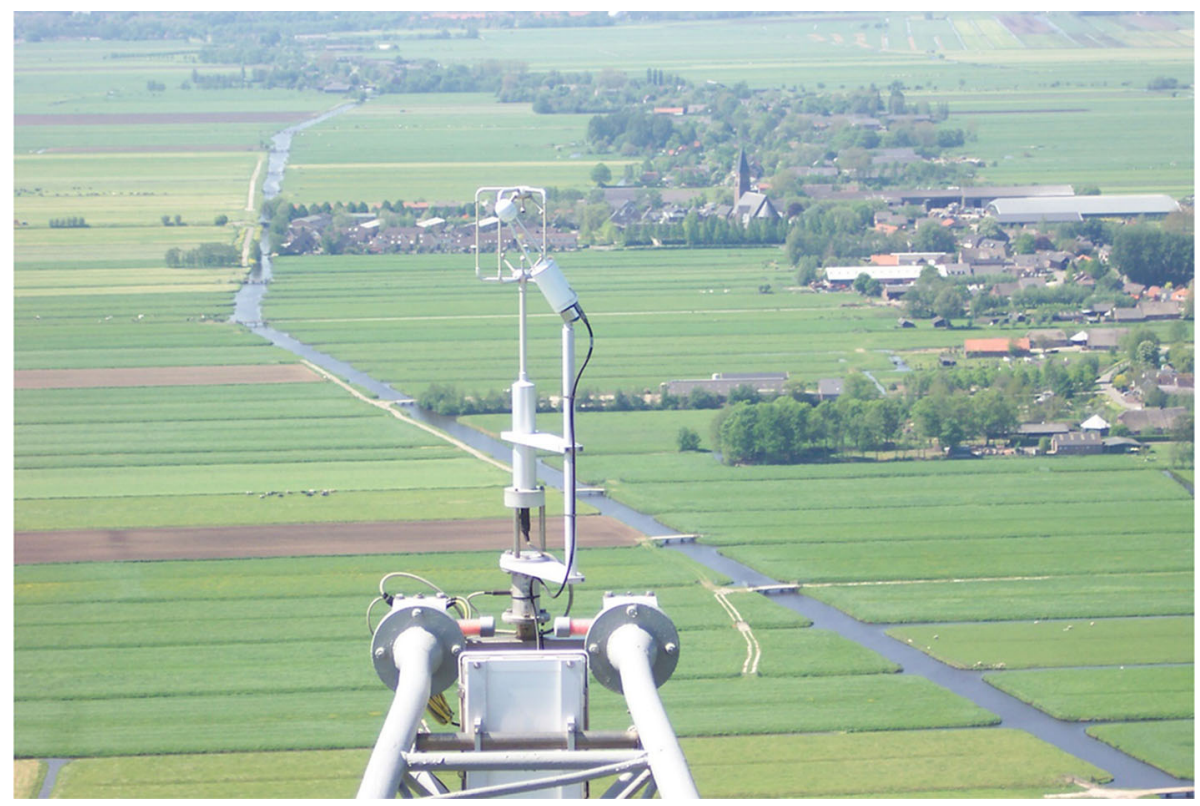

Fig. 2 View to the south-west with turbulence instruments for measuring regional-scale fluxes of momentum, sensible and latent heat, and carbon dioxide. (Photo by Fred Bosveld)

\subsubsection{Surface Radiative Temperature}

The behaviour of the temperature at the interface between the land surface and the air plays an essential role in understanding the exchange processes between the vegetation/soil system and the atmosphere. Two surface radiation-temperature sensors (Heitronic KT15) are operated: one at $2 \mathrm{~m}$ above the location of the soil temperature observations at the EB field, measuring the temperature of a $1 \mathrm{~m}^{2}$ grass area, and another one looking down from the 200-m level to the EB-field. The latter has a "footprint" of $10,000 \mathrm{~m}^{2}$, which is of similar magnitude as the representative area of the surface EC observations. The instruments are calibrated by the manufacturer. Each 3 months the instruments are checked at the KNMI calibration laboratory for proper functioning and calibration stability. Another estimate of the surface radiative temperature is derived from the longwave upward radiation measurements at the EB-field.

\subsubsection{Visibility}

Visibility is measured at six levels along the 200-m tower, with BIRAL SWS-100 scattering sensors. Measurement heights are similar to those of wind, temperature, and humidity. The instrumental set-up of this fog observational program is inspired by Bergot et al. (2005), who used this for the improvement of fog prediction at airports. Also an extension of the radiation observations at the surface is implemented, by measuring longwave and shortwave incoming radiation at the top of the tower $(213 \mathrm{~m})$. This involves the same type of instruments as at the EB-field. These additional radiation measurements allow for monitoring of the radiative properties of thin fog layers from above. 


\subsubsection{Infrasound}

An international network of infrasound observations exists, which emerged as a monitoring requirement for the nuclear test-ban treaty. With infrasound arrays nuclear detonations can be detected, but atmospheric applications are possible as well. From the point of view of infrasound, atmospheric turbulence itself is the one cause of noise. Reversely, signs of turbulent activity as detected by infrasound arrays may be of interest for atmospheric research (Cuxart et al. 2016), for example, for the detection of gravity waves. At Cabauw an array of micro-barometers is deployed (Smink et al. 2019), consisting of 10 sensors at the surface over an area of $600 \times 400 \mathrm{~m}^{2}$, and, quite uniquely, by five sensors at the $200-\mathrm{m}$ tower, which makes it the only $3 \mathrm{D}$ infrasound array in the world.

\subsection{Datasets}

All data undergo quality controls, with automatic controls performed at various stages of the data logging process. As a final step, many of the data streams are checked through visualization, and erroneous data are flagged. The quality control procedures differ among the instruments. For example, the standard wind, temperature and humidity observation in the mast follow the automatic quality control procedures as also implemented in the meteorological network. These instruments and their automatic quality controls are very robust and only on rare occasions do further manual checks lead to further rejection of data. In contrast, the turbulence data are disturbed by rain, fog and dewfall. Despite the application of algorithms for spike detection and signal stability, quite often remaining erroneous data have to be flagged manually.

KNMI and CESAR have a long tradition in freely distributing the observational data of the site; originally in print, later by floppy-disk, and nowadays through the internet. Most ABL observations are available from the CESAR database system (www.cesar-database.nl). The data are grouped in thematic datasets, and are available in NetCdf format following the climate and forecast convention.

Also available are gap-filled datasets. At the basis of the gap-filled surface energy dataset are the robust estimates of sensible heat flux by the gradient method, and of latent heat flux by the SEB residual method (Beljaars and Bosveld 1997). In the new observational program since 2000, the estimate of sensible heat flux is based on the EC method as this method is also quite reliable with only a small fraction of gaps. This is in contrast to the EC method for latent heat flux, which suffers from many more gaps in its time series. Thus, for latent heat flux, the SEB residual method is retained in the current gap-filled dataset.

Gap-filling for the Cabauw data is physically based and relies heavily on the modelling, scaling and parametrization work of Holtslag and Van Ulden (1983), Van Ulden and Holtslag (1985), Holtslag and de Bruin (1988), and Beljaars and Holtslag (1991). The current gapfilling procedures is still done following Beljaars and Bosveld (1997), but details differ due to changes in equipment. New is the gap-filled $\mathrm{CO}_{2}$ surface flux, where gaps are filled with an assimilation/respiration model as described in Jacobs et al. (2007).

\subsection{Key Complementary Observations}

At the Cabauw site, a very comprehensive set of instruments is brought together by the CESAR consortium. The instruments described in the previous Section are related to observing the structure and dynamics of the ABL. Other instruments in the measurement program 
are also important for studying the $\mathrm{ABL}$, as they provide information on the environment in which the ABL resides. Here we describe briefly these other instruments in as far as they provide continuous observations.

At the BSRN-field, high accuracy radiation measurements are performed, including hemispheric shortwave and longwave radiation, and direct and diffuse shortwave radiation. Also available are spectral observations of solar radiation. A hemispheric fish-eye visible light camera, and a scanning pyrometer (Nubiscope) give information on cloud fraction also during night time.

In the main building of the 200-m tower an aerosol laboratory is operated that draws air from the roof level at about $4 \mathrm{~m}$ above the surface and from an inlet at 60-m height. Also in the main building a greenhouse gas laboratory is operated which sucks air from four levels: 20, 60,100 , and $200 \mathrm{~m}$ (Vermeulen et al. 2011). Concentrations of $\mathrm{CO}_{2}, \mathrm{CH}_{4}, \mathrm{CO}, \mathrm{N}_{2} \mathrm{O}$ and $\mathrm{SF}_{6}$ are measured and stored as half-hourly values, whilst $\mathrm{Rn}^{222}$ is measured at two levels. These observations are part of the Integrated Carbon Observations System, a European research infrastructure. Their accuracy allows for interpreting these measurements in terms of sources and sinks in the region around Cabauw. At the top of the 200-m tower a drizzle radar is operated in horizontal scanning mode; it has a high spatial resolution and a range of $15 \mathrm{~km}$.

At the remote sensing site a number of active instruments are deployed. Two cloud radars are operated, one at $35 \mathrm{GHz}$ and one at $1.3 \mathrm{GHz}$, the first being sensitive to cloud droplets, the latter being more sensitive to raindrops. In the optical range a UV lidar and a near-infrared lidar are operated; the UV lidar has a polarization channel that further enhances its capability in aerosol detection. Both optical instruments provide further information on clouds and aerosols. A Raman lidar is operated on a campaign basis, and provides profiles of humidity and aerosols, whilst a microwave radiometer gives information on humidity and liquid water. Together with the near-infrared lidar and the $35-\mathrm{GHz}$ cloud radar it forms the basis for the cloud product as generated by CLOUDNET. Also operated is a cloud video camera.

\section{Research}

The comprehensive Cabauw observational program opens up much more pathways into science than can be handled by one institute alone. By disseminating the Cabauw data freely, many atmospheric scientists from around the world have used the data in their own research. From the general science perspective, this is an efficient way to exploit the potential of such an observatory. Here we give a small selection of research results obtained over the last 2 decades.

\subsection{Exploiting the Long Time Series}

\subsubsection{Climatology}

The long atmospheric time series of Cabauw can be used to characterize the local climate for parameters that go beyond the traditional surface observations of wind, temperature and humidity. As an example, Fig. 3 shows the yearly-averaged surface evaporation over the period 1986-2019. The values of the first period (1986-1996) are based on the processing described by Beljaars and Bosveld (1997). Also the unstressed reference evaporation is shown according to the formulation of Makkink (De Bruin and Lablans 1987), based on an empirical formulation with solar radiation and temperature as input. The strong correlation between 
Fig. 3 Yearly-averaged actual (OBS) and reference (REF) surface evaporation rates over the period 1986-2019. The 1986-1996 values are based on the processing described in Beljaars and Bosveld (1997). It should be noted that the periods 1986-2019 and 2001-2019 have different instrumentation and different bias correction procedures. A further study of the effect of instrument change on biases will be necessary before firm conclusions can be drawn

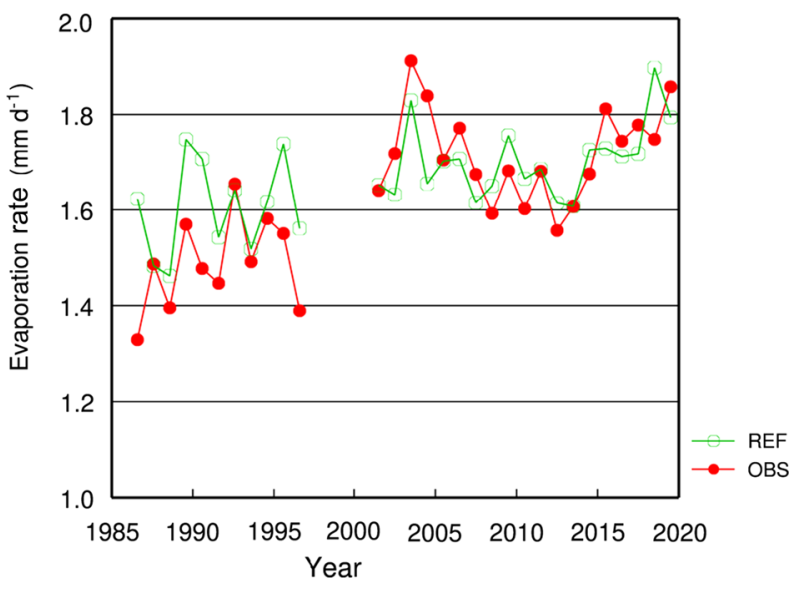

observed evaporation and reference evaporation and the reasonable match between the two, confirms that for this well-watered site, evaporation is energy limited and that irradiation is the most important driver of evaporation. A positive trend is seen in actual evaporation, which is mostly reflected in the reference evaporation. The trend in reference evaporation is due to positive trends in temperature and irradiation (Jacobs et al. 2010; Van der Schrier et al. 2011; Boers et al. 2015). Although trends are seen, part of the signal may derive from the improvement of instrumentation and the change of bias-handling procedures between the two observation periods. A further comparison study of instruments is necessary before firm conclusions can be drawn. Long time series of surface energy budgets are obviously of interest for many studies, a clear example being the study of Teuling et al. (2010) in which the response of forest and grassland to heat waves is explored.

\subsubsection{Stratification of Data}

The long time series of Cabauw enables the stratification of the data in terms of external parameters, and the study of the response and development of the ABL. A climatology of low-level jets (LLJ) at Cabauw was derived by Baas et al. (2009) showing that in $20 \%$ of the nights LLJs occur. Evaluation of the ECMWF 40-year re-analysis (ERA-40) shows that LLJs in ERA-40 are less frequent and situated at a higher level than in the observations. Also, the wind turning across the boundary layer is smaller than observed and the speed of the LLJ is underestimated (e.g., Svensson and Holtslag 2009). This is attributed to mixing being too strong in the ERA-40 model during stably stratified conditions. Van de Wiel et al. (2010) extended the concept of the frictionless inertial oscillation (Blackadar 1957) above the nocturnal boundary layer (NBL) to oscillations in the NBL where friction plays a role. Baas et al. (2012) were able to confirm this result from the long time series of Cabauw and a comprehensive single-column model (SCM) of the atmosphere.

Donda et al. (2013) showed that a relatively simple conceptual model of the NBL in interaction with the surface is able to reproduce ensemble temperature and wind profiles for various classes of geostrophic wind speed and longwave radiative cooling. Van Hooijdonk et al. (2015) were able to define a single parameter (the so-called shear capacity) to distinguish between very stable and weakly stable turbulent nights. Van der Linden et al. (2017) classified the clear-sky NBL according to geostrophic wind speed. For each geostrophic wind speed 
Fig. 4 Evolution of sensible heat flux during the evening transition, where $t$ is time each side of the transition. Data are classified according to geostrophic wind-speed classes. Blue represent low and red high geostrophic wind speeds. (From Van der Linden et al. 2017)

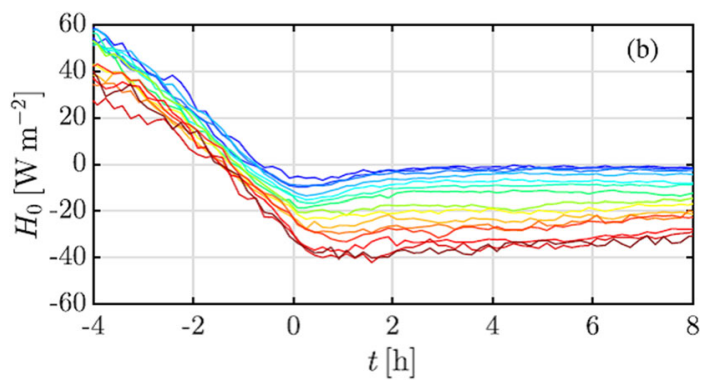

class an ensemble-averaged time development of the state variables and surface fluxes is obtained (Fig. 4).

\subsubsection{Wind Energy}

The increasing importance of wind energy has generated many studies into the relation between surface weather conditions and winds at increasingly higher levels (Gryning et al. 2007). Holtslag (1984) already showed on the basis of Cabauw wind observations that, especially under stable conditions, extrapolation with surface-layer scaling becomes problematic at heights of $100 \mathrm{~m}$. This is surprisingly high given that surface-layer scaling under stable conditions is expected to apply only in the first few tens of metres of the atmosphere. Monahan et al. (2012) studied the probability density functions of wind speed at elevated levels on the basis of Cabauw and Los Alamos (USA) observations. They found that the occurrence of intermittency in the stable boundary layer has a strong effect on these wind speed distributions. Optis et al. (2014) showed that a two-layer model that accounts for stability effects in, and for Coriolis effects above, the stable surface layer gives a better representation of wind profiles under stable conditions. Baas et al. (2016) showed that stability effects on the wind profile can be even stronger over sea than over land. Basu (2018) derived a method to estimate atmospheric stability from wind-profile observations alone, which is especially of interest for wind-energy applications when only wind-profiler data are available. The method was tested on Cabauw observations.

Wind atlases are based on runs of numerical weather prediction (NWP) models performed in hindcast mode, and provide detailed information on wind velocity at elevated levels suitable for the use in wind-resource assessments. The KNMI North-Sea Wind atlas and recently the Dutch Offshore Wind Atlas (Wijnant et al. 2019) are constructed on the basis of long runs of the mesoscale model HARMONIE (Bengtsson et al. 2017) embedded in the ERA5 reanalysis of the European Centre for Medium-range Weather Forecasting (ECMWF). Both atlases are evaluated on the basis of, among others, observations from the Cabauw tower (Knoop et al. 2019).

\subsection{Model Evaluation}

The use of observations in atmospheric model development is often indirect. Individual processes are studied with dedicated observations and dedicated models that may lead to a better understanding of the process. The next step is the incorporation of this new knowledge into the atmospheric model, and often involving simplifying or parametrizing certain aspects of the dedicated model. Model evaluations come in various forms, and also the role of 
observations in the evaluation may vary. The use of direct local observations for model evaluation is quite challenging, but substantial progress has been made over the years, as will be shown by the following examples.

\subsubsection{The Project for Intercomparison of Land-surface Parametrization Schemes}

The Project for Intercomparison of Land-surface Parametrization Schemes (PILPS) started in 1992 under the umbrella of the Global Energy and Water Cycle Experiment (GEWEX) and the Working Group on Numerical Experimentation (Henderson-Sellers et al. 1995). In Phase 1, 26 offline surface schemes were compared by forcing them with a synthetic time series, while phase 2 was meant to compare surface schemes with real observations. At the PILPS workshop in Yokohama, 1993, the Cabauw dataset was chosen for this comparison for three reasons. First, three land-surface types were envisioned throughout this phase and Cabauw was a useful case representing mid-latitude homogeneous grassland. Second, at Cabauw, deep soil is saturated throughout the year and evaporation is seldomly limited by water supply (cf. Fig. 3). This would then prohibit the divergence of models with respect to their description of soil water. Third, the Cabauw data included, which at that time was quite rare, a full year of surface latent heat and sensible fluxes enabling testing of seasonal variations.

Within this PILPS Phase 2 project, it was found quite challenging to confront the models with Cabauw observations. To name a few: soil and vegetation characteristics had to be quantified, these parameters had to be translated into model parameters, and the observations come with only partially documented measurement and representativeness errors. After a 30month period with many iterations the dataset was described by Beljaars and Bosveld (1997) and the results of the intercomparison were described in Chen et al. (1997). Figure 5 shows the spread among the models with regard to the distribution of net radiation over sensible and latent heat fluxes. Much has been learned from this intercomparison study and in the years that followed, many model groups have used the dataset to test and improve their landsurface models (Schulz et al. 1998; Chang et al. 1999). For Cabauw, one important outcome was the creation of a gap-filled dataset, based on a physically-based parametrization scheme. Another outcome was the realisation that seasonal changes in soil hydrology at Cabauw is important, despite the seemingly simple soil hydrology due to management of the water table in the ditches at the site. This resulted in the addition of soil hydrological observations to the observational program.

\subsubsection{GABLS}

The GEWEX atmospheric boundary-layer studies (GABLS) has focused since its start on bringing together the international ABL community on the subjects of stable atmospheric boundary layer and the diurnal cycle, by defining case studies for model intercomparison (Holtslag et al. 2013). The first two studies were based on idealized cases, but at the GABLS workshop in Stockholm, 2007, it was decided that the GABLS3 case would be derived from the long-term Cabauw data archive, and that the models would also be compared to observations. From GABLS2 it was learned that prescribing realistic pressure gradient forcing and advective tendencies, as well as using an interactive surface scheme, was essential in a meaningful comparison with observations.

In the GABLS3 case a 24-h period was needed centred around midnight, and 6 years of data (2001-2006) were examined to select a suitable case for GABLS3. To avoid conditions 


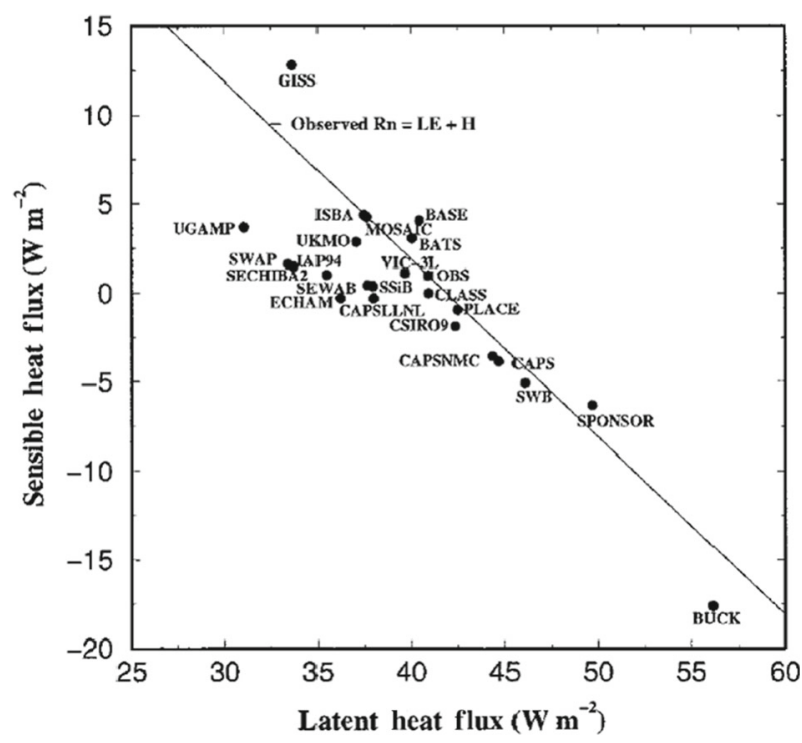

Fig. 5 Annual-averaged sensible versus latent heat flux for 23 land-surface schemes and the observed value (OBS). The line represents points with annual mean net radiation equal to the observed value $\left(41 \mathrm{~W} \mathrm{~m}^{-2}\right)$. Based on Cabauw 1987 observations for PILPS 2a. (From Chen et al. 1997)

with undesirable complexity, the ideal case had to satisfy at least three criteria: a stationary synoptic situation, clear skies, and the absence of fog. Additionally, a significant surface inversion must develop after sunset with a distinct LLJ directly aloft. For the development of a substantial LLJ a moderate geostrophic wind speed of about $7 \mathrm{~m} \mathrm{~s}^{-1}$ is favourable (Baas et al. 2009). After applying these selection criteria, nine potential cases remained of which one was selected.

For the case prescription, the geostrophic forcing was derived from the pressure observations in the national network, and advective fluxes derived from a combination of the outcome of a NWP model and observed tendencies in wind, temperature and humidity at the $200-\mathrm{m}$ level of the meteorological mast. See Bosveld et al. (2014a) for further details on the case description.

As expected, the prescription of the advective terms in the GABLS3 case was found to be essential for an SCM evaluation (Bosveld et al. 2014b), and indeed a comparison with observations turned out to be possible. To explain differences among models, use was made of so-called process diagrams. Figure 6 shows the relation between the wind-speed maximum and the backing of the wind direction with the nocturnal boundary-layer height. The results of sensitivity runs with a reference model clearly indicate that the strength in nocturnal turbulent mixing explains much of the spread among models in the two diagrams.

After the case description of GABLS3 was finalized, Baas et al. (2010) studied the possibility of using composite cases for doing SCM evaluations. The idea was that such composite cases may suffer less from inaccuracies in the prescribed advection terms. Indeed, by using eight comparable LLJ nights from the long Cabauw data record the composite case enabled an improved differentiation with respect to performance between different model formulations. 

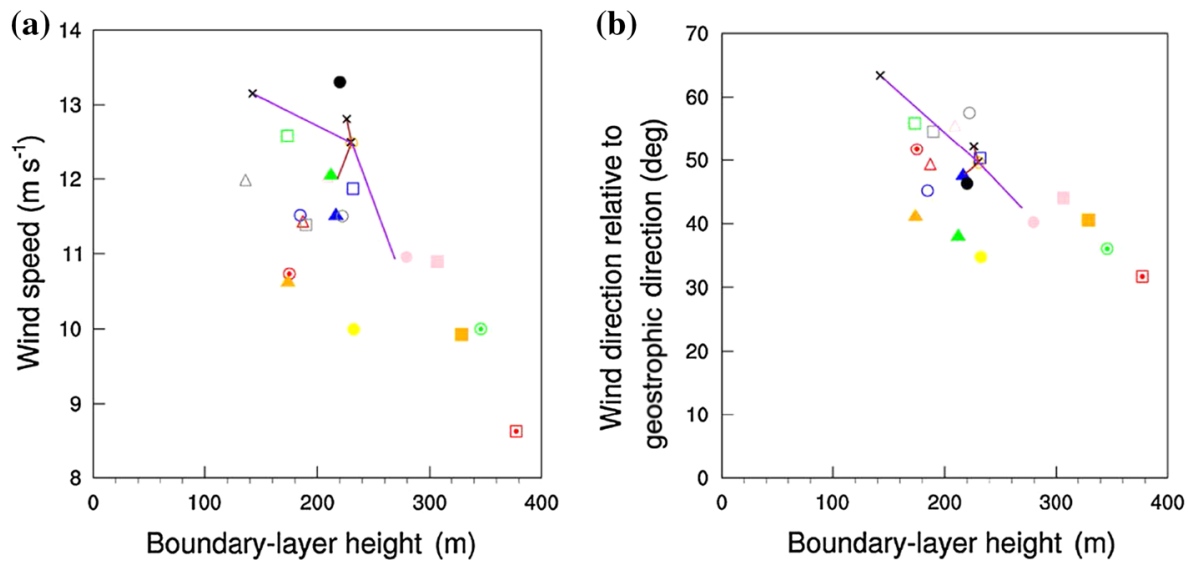

Fig. 6 Relation between boundary-layer height after midnight (0000-0200 UTC) and, a night-time wind-speed maximum, and $\mathbf{b}$ maximum backing of the surface wind relative to the geostrophic wind. The boundary-layer height is estimated from vertical temperature profiles. In both graphs closed symbols represent strongly mixing models. The purple lines represent sensitivity of a reference model for changes in the turbulent mixing parametrization. (From Bosveld et al. 2014a, b)
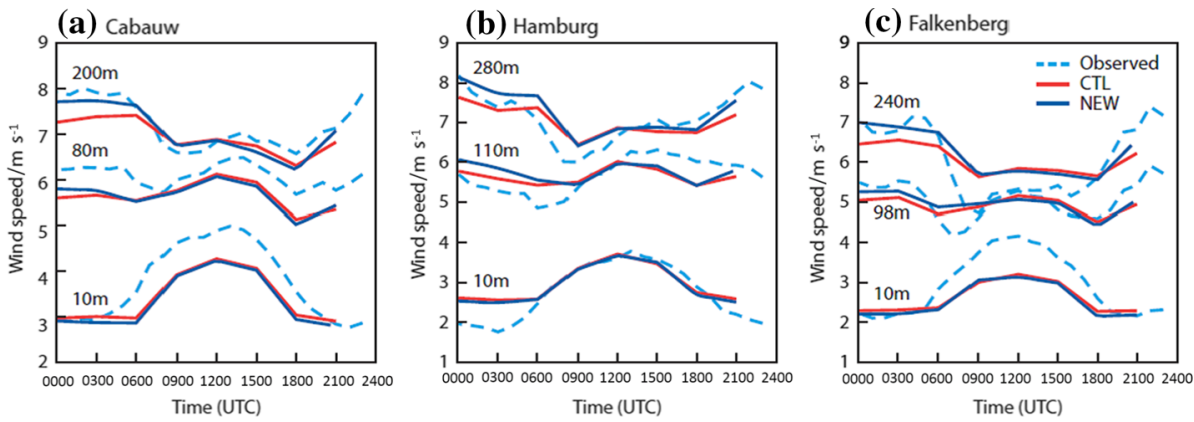

Fig. 7 Averaged diurnal cycle of wind speed at, a Cabauw, b Hamburg, and c Falkenberg from forecasts produced in the control (CTL) and NEW experiments (lead times 24 to $42 \mathrm{~h}$ ) compared to observations (blue dashed). Results are shown for June to August when the diurnal cycles are the most pronounced. (From Sandu et al. 2013a)

\subsubsection{ECMWF}

Already in the 1980s a close connection was established between Cabauw and ECMWF, with Cabauw observations used for the evaluation of the ECMWF model and for the improvement of model parametrizations. The first ECMWF re-analysis (ERA) covered the 25-year period 1979-1993. Bosveld et al. (1999) evaluated this re-analysis with Cabauw observations. The evaluation included: precipitation amount, cloud cover, cloud transparency, surface fluxes, and ABL profiles. Sandu et al. (2013a, b) made improvements on the turbulence scheme of the ECMWF model that resulted in a better representation of wind profiles in the lowest few $100 \mathrm{~m}$ of the atmosphere. Observations from tall towers, in this case Lindenberg, Hamburg and Cabauw, played an essential role in the development and evaluation of this new model version (Cy40) as shown in Fig. 7. 


\subsubsection{KNMI parametrization testbed}

To facilitate model evaluation on a regular basis, Neggers et al. (2012) developed the KNMI parametrization testbed. The KNMI parametrization testbed is part of a general trend towards a more statistically significant process-level model evaluation, with the purpose of optimizing the identification of problems in general circulation models that are related to parametrization schemes. In the KNMI parametrization testbed, continuous long-term SCM runs and largeeddy simulations (LES) using the Dutch Atmospheric Large-Eddy Simulation (DALES) (Heus et al. 2010) model, are evaluated against observations at multiple time scales (Fig. 8). The authors show that, by using this method, it becomes possible to reproduce typical longterm mean behaviour of the physical processes with short time scales in larger-scale models, while still preserving the benefits (e.g., model transparency) of a single-column model. It is argued that this strategy facilitates the tracing and understanding of errors in parametrization schemes, which eventually lead to a reduction of related uncertainties in numerical predictions of weather and climate. It is foreseen that the KNMI parametrization testbed will play an essential role in the Ruisdael project described in Sect. 5.

\subsection{Satellite Validation}

Satellite-based passive remote sensing observations of the atmosphere have had a tremendous impact on our ability to understand and predict the Earth's atmosphere. Here we focus on land-surface applications.

An intensive field campaign was held in 2006 in the Netherlands to support the advance of modelling of land-surface hydro-meteorological processes (Su et al. 2009), in particular the exploitation of angular effects in land-surface observations from satellites. The objective of the campaign was to build a database for the investigation and validation of the retrieval of bio-geophysical parameters, obtained at different radar frequencies (X-, C- and L-Band) and hyperspectral optical and thermal bands. The data were acquired simultaneously over contrasting vegetated fields, forest (Loobos and Speulderbos), and grassland (Cabauw) in the Netherlands. As such, all activities were related to algorithm development for future satellite missions such as the Sentinels, and for validation of retrievals of land-surface parameters with optical, thermal and microwave sensors on-board current and future satellite missions.

A reference evapotranspiration product is routinely available from Meteosat Second Generation (MSG) observations (Trigo et al. 2018). It is based on the MSG surface incoming radiation product and on surface temperature fields from the ECMWF model. Cabauw evaporation measurements played, among others, an important role in the development and testing of this product (De Bruin et al. 2016).

\subsection{Process Studies}

The comprehensive observational program at Cabauw makes it particularly well-suited for process studies, which are key to obtaining quantitative understanding, and supporting the design parametrizations for large-scale models (see Sect. 4.2). Here some typical examples of process studies are presented. 


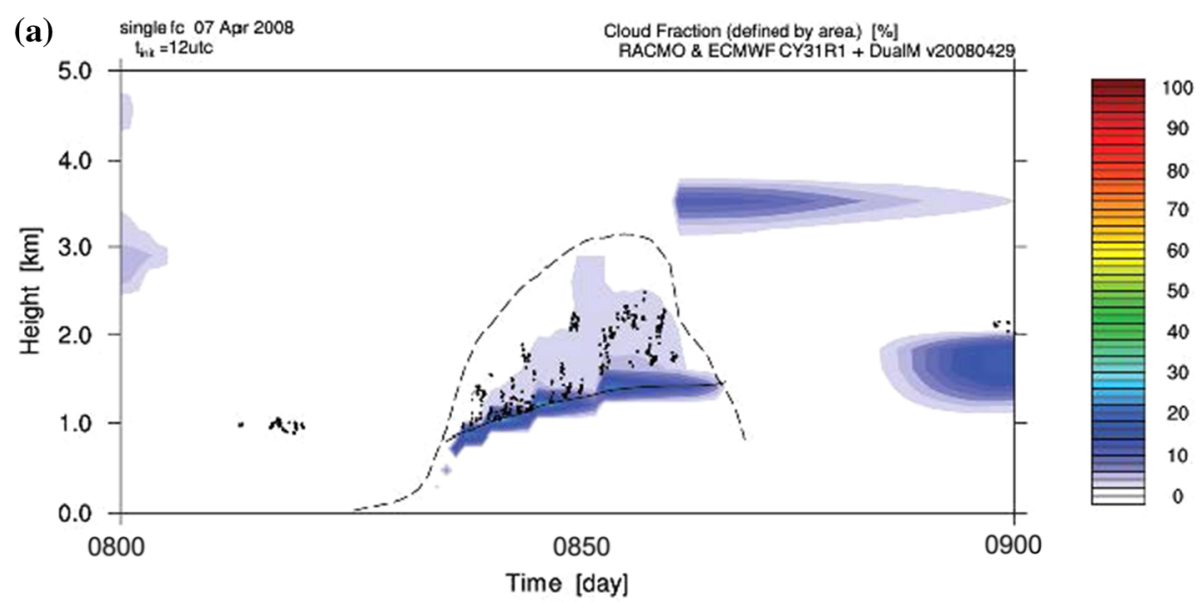

(b)

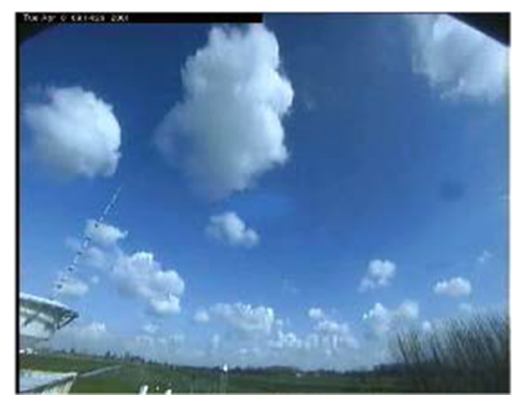

(c)

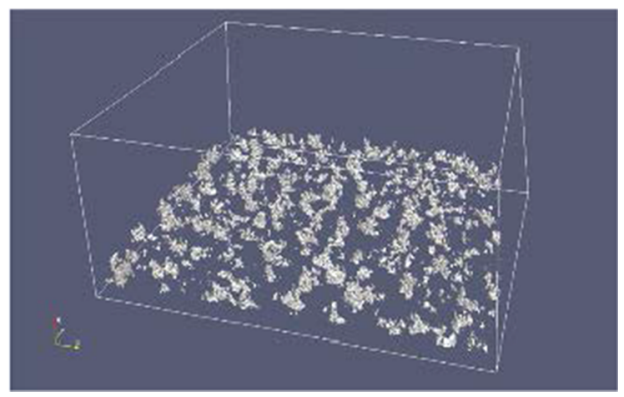

Fig. 8 An example of a single case process-level study with the KNMI parametrization testbed, showing model output and measurements on 8 April 2008 at Cabauw. a Time-height contour plot of an SCM's cloud fraction (shaded) overplotted by the lowest cloud-base height as observed by the CT75k ceilometer (black dots). The lifting condensation level (solid line) and the termination height (dashed line) of the strongest model updraft are also shown, for reference. b A photo taken by the north-looking Cabauw webcam on 8 April 2008. The tower can be seen on the left, with the cloud radar in the foreground. c A snapshot of the 3D cloud field as produced by the LES model for this day. (From Neggers et al. 2012)

\subsubsection{Mesoscale Studies}

Verkaik and Holtslag (2007) extended earlier work of Beljaars et al. (1983) showing, from tower flux observations, that the regional-scale roughness is larger than the local roughness of the grassland, due to the presence of obstacles such as tree rows and buildings. This is of importance when evaluating models with Cabauw observations. The long turbulent time series at Cabauw have also contributed to a better quantification of the spectral behaviour between the resolved mesoscales and the turbulent scales (Schalkwijk et al. 2015), and to how LES embedded in large-scale meteorological models is able to better resolve the small scales in the region of the Cabauw site.

With the North Sea and Lake IJssel at distances of $50 \mathrm{~km}$, Cabauw is located in a complex topographical setting, which gives rise to mesoscale modulations of the large-scale synoptic flow. Tijm et al. (1999) studied the vertical structure of sea-breeze fronts over Cabauw from wind-profiler observations and were able to quantify the return flow that occurs at elevated 
heights. Wichink Kruijt et al. (2004) studied scaling relations for the sea-breeze intensity. In Steele et al. (2014) sea-breeze occurrences at five locations around the North Sea coasts were studied for the relevance to offshore wind energy, showing that three different types of sea breezes can be distinguished. Jiménez et al. (2016) studied the role of synoptic scale and mesoscale on the evolution of the boundary-layer wind profile over the coastal region of Cabauw. On the basis of a 10-year run of the Weather Research and Forecasting model and Cabauw observations they were able to identify a near-coast diurnal acceleration. The ABL winds show a strong intra-diurnal component that is characterized by an oscillation of the near-surface flow around the geostrophic direction with the maximum departure in the afternoon. Although also driven by thermal land-sea differences, this mesoscale component is not associated with the classical concept of a sea-breeze front. Arrillaga et al. (2018) studied occurrences of sea-breeze fronts at Cabauw and found from $\mathrm{CO}_{2}$ concentration observations that recirculation of continental air in these fronts may occur.

Angevine et al. (2001) used surface flux, tower and wind-profiler observations to study the morning time transition from the stable to the convective boundary layer, they found that the warming of the stable boundary layer is only partly through direct surface heating. The largest contribution is from shear-driven entrainment which is stimulated by the reduction of the surface-layer stability through surface heating. Vila-Guerau de Arellano et al. (2004), based on aeroplane observations and in situ observations from Cabauw, were able to quantify the effect of entrainment on the $\mathrm{CO}_{2}$ concentration in the ABL. It was found that especially in the morning the evolution of the $\mathrm{CO}_{2}$ concentration is dominated by the entrainment process rather than by the surface assimilation. Casso-Torralba et al. (2008) exploited the turbulence observation in the 200-m tower flux to assess the budgets of sensible heat and $\mathrm{CO}_{2}$ fluxes in the ABL. Under non-advective conditions the vertical flux divergence will be in equilibrium with the time rate-of-change of temperature and $\mathrm{CO}_{2}$ concentration in the $\mathrm{ABL}$. A deviation of this equilibrium indicates the presence of advection. Figure 9 shows time series of ABL temperature and $\mathrm{CO}_{2}$ concentration, and also shown for both quantities are the time series derived from the flux divergence observed along the 200-m tower, representing the values that would occur when no advection is present. Clearly, the temperature observations indicate no heat advection, whereas the $\mathrm{CO}_{2}$ concentration measurements indicate advection of $\mathrm{CO}_{2}$ for this day.

\subsubsection{Evaporation and Its Link To Photosynthesis}

Van Heerwaarden et al. (2010) developed a method to analyze the daily cycle of surface evapotranspiration. It quantifies the influence of external forcings as radiation and advection, and of internal feedbacks induced by boundary layer, surface layer, and land-surface processes on evapotranspiration. A budget equation for evapotranspiration is derived by combining a time derivative of the Penman-Monteith equation with a mixed-layer model for the convective boundary layer. Analysis of measurements at CESAR and Niamey (Niger, semi-arid) and model results show that evapotranspiration is initiated by solar radiation but is significantly regulated by the ABL and the land surface throughout the day. In particular the entrainment of dry air can increase the evaporation beyond its thermodynamic equilibrium value. At CESAR the variations of moisture and temperature in the atmosphere played an equally important role, while at Niamey the effect of temperature fluctuations dominated the feedbacks and moisture fluctuations become irrelevant.

The comprehensive dataset of Cabauw enabled the investigation of the partition between evapotranspiration and sensible heat flux modulated by the vegetation. The first surface flux is strongly regulated by the capacity of the grassland in regulating the $\mathrm{CO}_{2}$ assimilation and 


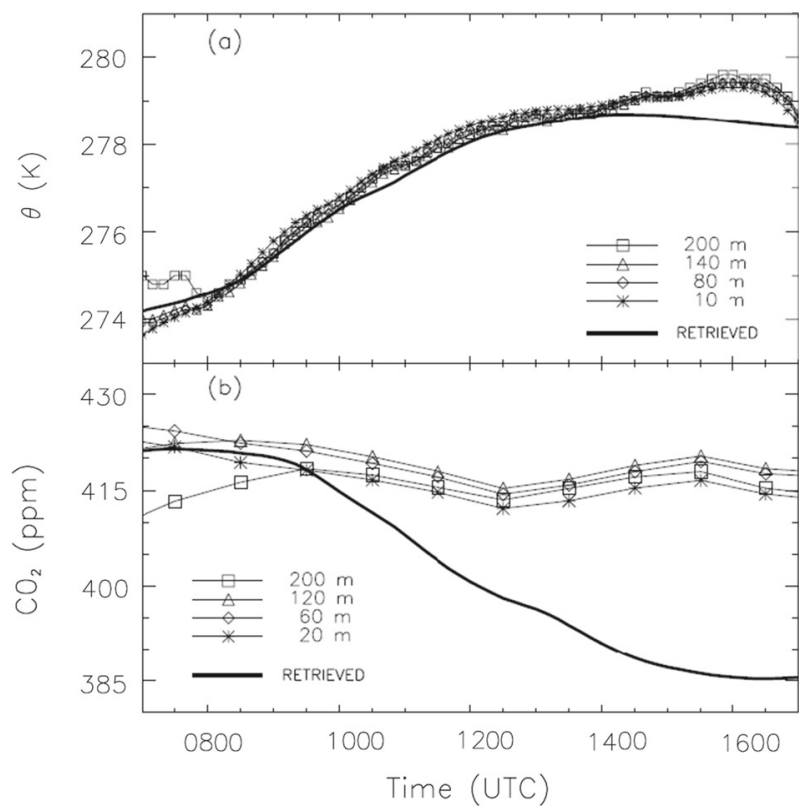

Fig. 9 Diurnal time evolution of, a 10-min mean potential temperature $\theta$, and b hourly mean $\mathrm{CO}_{2}$ mixing ratio during 12 March 2004. The thick solid line represents the retrieved $\theta$ and $\mathrm{CO}_{2}$ values using the observed vertical flux divergence along the $200-\mathrm{m}$ tower and under the assumption of no advection. The results indicate presence of $\mathrm{CO}_{2}$ and absence of heat advection. (From Casso-Torralba et al. 2008)

plant transpiration. Constrained and validated by the Cabauw data, Vilà-Guerau de Arellano et al. (2012) and Sikma et al. (2019) carried out investigations on how the surface and boundary-layer dynamics will behave under future climate scenarios characterized by enhanced $\mathrm{CO}_{2}$ concentration and higher temperatures. Their findings indicate that a futureclimate mimicking simulation shows minimal changes in the regional energy balance due to offsetting effects between increased temperature and $\mathrm{CO}_{2}$ concentration, while plant photosynthesis increased and transpiration decreased. The ABL was drier, even though surface fluxes were very similar current conditions, thereby hampering cloud formation and development. Super et al. (2015) study the interplay between evaporation and boundary-layer clouds as modulated by the cumulative ozone effect.

\subsubsection{Fog}

From the start, fog has been an active research area at Cabauw. Wessels (1979) analyzed observations of an advective fog case, and Duynkerke (1991a, b, 1999) used a SCM to study radiation fog. With increasing computer power it is now possible to use LES models at sufficiently high resolution to resolve the relevant turbulent scales in the stable boundary layer. Maronga and Bosveld (2017) showed how well a high resolution LES model could simulate a typical radiation fog night at Cabauw. They found that turbulent mixing has a strong impact on the time of fog formation, which is complicated by the interaction with both radiative cooling and water vapour removal by dew deposition. Furthermore, it was found that the near-surface soil temperature plays a key role for the exact time of fog formation, whereas near-surface soil moisture is decisive for the lifting and dissipation time of the fog layer. 


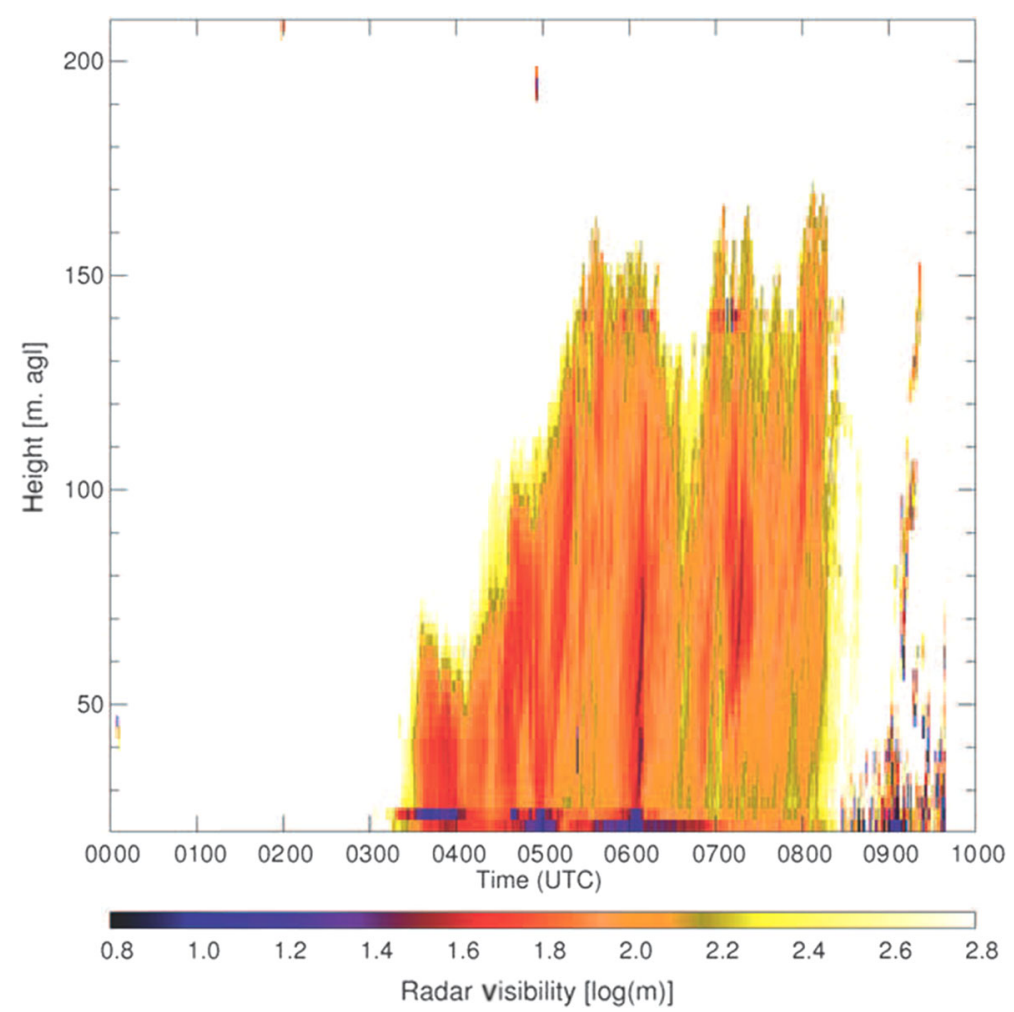

Fig. 10 Time-height diagram of fog visibility estimates from the backscatter signal of a slanted 35-GHz cloud radar. Slanting angle is $0.05 \mathrm{rad}$ (3o). (From Boers et al. 2013)

More recently, Boers et al. (2013) modelled the evolution of the microphysics of a radiation fog layer that was observed with in situ instruments and radar at CESAR on March 23, 2011 (Fig. 10). The onset phase and the evaporation phase of the fog produce different radar reflectivity-visibility relationships. A droplet activation model used the aerosol size distribution observed at $60-\mathrm{m}$ altitude as input, and radar reflectivity and visibility were calculated from model drop-size spectra using Mie scattering theory. Since radiative cooling rates are small compared to cooling rates due to adiabatic lifting of aerosol-laden air, the modelled supersaturation remains low so that only few aerosol particles are activated to cloud droplets. The results suggest that the different radar reflectivity-visibility relationships are the result of differences in the interplay between water vapour and cloud droplets during the formation and evaporation of the fog. During droplet activation, only a few large cloud droplets remain after successfully competing for water vapour with the smaller activated droplets. These small droplets eventually evaporate (deactivate) again. In the fog dissolution/evaporation stage, only these large droplets need to be evaporated. Therefore, to convert radar reflectivity to visibility for traffic safety products, knowledge of the state of local fog evolution is necessary.

Izett et al. (2019) developed a method to detect fog at levels below the usual observation height (ground fog). The method makes use of a vertical array of light-emitting diodes and a video camera, and by combining this with a distributed temperature sensor detailed vertical temperature profiles could be determined to interpret these visibility observations. 


\section{The Future of Tall Towers for Atmospheric Research}

In the late 1960s sonic detection and ranging (sodar) was the first remote sensing technique developed for probing the ABL. These instruments measure profiles of the structure parameter of sonic temperature and of wind. In the following decades also radar techniques were developed. This enabled the detection of clouds, precipitation and wind. Lidar techniques in the ultraviolet, visible and near infrared range gave way to the detection of clouds, aerosols, water vapour, various gas species and even temperature. Clear advantages of remote sensing techniques are the height range over which observations are obtained and the flexibility with respect to the location of operation. On the other hand, vertical resolution is limited, which is in particular problematic in the lowest few hundred metres of the atmosphere where vertical gradients are steepest. But also here promising new remote sensing techniques are developed, such as 3D wind scanners (Fuertes et al. 2014; Vasiljevic et al. 2016) that enable the profiling of 3D turbulence.

An advantage of towers is that they provide a platform for robust instruments that operate even under adverse weather conditions, making them very well suited for the registration of long continuous records, a requirement which is often much more difficult to meet with remote sensing observations. Moreover, for tracers, i.e. gases or aerosols, often no remote sensing technique is yet available, or the required accuracy in terms of concentration is not sufficient.

It is clear that tower observations and remote sensing measurements can complement each other nicely as is shown for example for the Lindenberg site by Neisser et al. (2002). This is also the prospect of the Ruisdael project (https://ruisdael-observatory.nl/), the large-scale atmospheric research infrastructure in the Netherlands (2018-2027) that will combine surface, mobile, tower, aeroplane, and remote sensing observations together with high-resolution simulations in order to become a 'virtual laboratory' for studying multi-scale processes in atmospheric chemistry and physics. By doing so, the Ruisdael Observatory is envisioned to improve the reliability of weather, air quality and climate models. The Cabauw site with its 200-m tower is central in this research facility due to the comprehensive surface and upper-air continuous observations.

In the past few years we saw the advent of overarching atmospheric research infrastructures at the European level. The Integrated Carbon Observations System aims at quantifying and understanding the greenhouse gas balance of Europe and neighbouring regions, and this infrastructure relies heavily on high-accuracy tower-based greenhouse gas concentration measurements of which the Cabauw tower is one. Also the European Research Infrastructure for the observation of Aerosol, Clouds and Trace Gases (ACTRIS) relies prominently on tower-based observations such as performed at Cabauw.

\section{Discussion}

To operate a research site such as Cabauw over a 50-year period has been a major challenge. The observations from the meteorological network are embedded in international agreements and budgets are secured. In contrast, for a research site such as Cabauw no such agreement forces the continuation of the observational program. Typically, every 10 to 15 years significant investments are needed in the infrastructure, instruments, and information technology. At these moments the continuation of the site is under debate and is weighted against other research options which have become relevant over time. Since the construction of the Cabauw 
Table 1 The international networks represented at Cabauw

\begin{tabular}{lll}
\hline Acronym & Organisation & Description \\
\hline ACTRIS & EU & Aerosols, clouds, and trace gases \\
AERONET & NASA & Aerosol retrieval through sun photometers \\
BSRN & GEWEX & Baseline Surface Radiation Network \\
CEOP & GEWEX & Coordinated Energy and water cycle Observation Project \\
CLOUDNET & EU & European pilot network for observing cloud profiles \\
C-SNRWP & EUMETNET & Data exchange program for model development \\
EARLINET & EU & European Aerosol Research Lidar Network \\
E-PROFILE & EUMETNET & Profiler and lidar network \\
E-WINPROF & EUCOS & Windprofiler network \\
GALION & GAW & Aerosol lidar observation network \\
GAW & WMO & Monitoring of trace atmospheric constituents \\
GRUAN & WMO-GCOS & Reference upper-air network \\
ICOS & EU & Integrated Carbon Observation System \\
MWRnet & EU-COST & International network of ground-based microwave radiometers
\end{tabular}

tower in 1970 three of these debates have taken place. The first was in the early the 1980s: at that time much unique observational material from the Cabauw site was archived and a number of fundamental research projects were underway that are still relevant today. Numerical weather prediction models were becoming operational and observations of the relevant landsurface atmosphere exchange processes were needed to evaluate such models. It was decided to have a continuous and long-term observational program of meteorological profiles, and the components of the surface radiation and heat budget for the benefit of such atmospheric model evaluation. This program was operated during the period 1986-1996, after which a new decisive moment occurred.

With the advent of remote sensing techniques, and increasing cooperation at the Cabauw site with other national institutes, it became clear that a basic meteorological measurement program was still needed at the site. This program, starting in 2000, has expanded over the years and runs until present as described in Sect. 3. The third decisive moment was quite recently when it became clear that after 50 years the tower infrastructure needed substantial revisions. Most notably the guy-wires had to be replaced and the hydraulic system had to be renewed. The granting of the Ruisdael project in 2018 turned out to be a sufficient incentive to perform these revisions. From this experience we may expect that by the end of the $2020 \mathrm{~s}$ a new decisive moment will occur.

Important factors that contributed to the continuation of the site over the last 50 years are the embedding of the site in international networks which are listed in Table 1. Also the comprehensive continuous measurement program regularly attracts field campaigns and experiments which are listed in Table 2. Cabauw data have been used in more than 450 peer-reviewed papers stressing its ongoing importance for atmospheric research.

In the same context it is essential to explain the relevance of Cabauw to society, and to make clear the pathways in which knowledge, generated with the help of Cabauw observations, is used for the benefit of society. Figure 11 shows a schematic of the flow of knowledge. Sometimes this connection is very direct, for example, in the case of the eruption of the Islandic volcano Eyjafjallajökull in 2010 (Donovan and Apituley 2013) and its direct effect 
Table 2 List of national and international campaigns conducted at Cabauw

\begin{tabular}{|c|c|c|}
\hline Acronym & Description & Years \\
\hline TEBEX & Tropospheric energy budget experiment & 1995 \\
\hline CLARA & Clouds and radiation & 1996 \\
\hline CaPRIX & Cabauw profile intercomparison experiment & 2000 \\
\hline Cliwa-Net & Cloud liquid water network & 2001 \\
\hline $\mathrm{BBC}$ & Cloud observation campaign & 2001 \\
\hline CREX-02 & CESAR rain experiment & 2002 \\
\hline $\mathrm{BBC} 2$ & Cloud observation campaign & 2003 \\
\hline DANDELIONS & Aerosol and nitrogen dioxide OMI and Sciamachy & 2005 \\
\hline SPE & Sound propagation experiment & 2005 \\
\hline DANDELIONS & Aerosol and Nitrogen Dioxide OMI and Sciamachy & 2006 \\
\hline EAGLE & $\begin{array}{l}\text { Exploitation of angular effects in land surface observations from } \\
\text { satellites }\end{array}$ & 2006 \\
\hline SatLink & $\begin{array}{l}\text { Linking satellite observations of aerosol optical depth with ground } \\
\text { level observations of particulate matter }\end{array}$ & 2006 \\
\hline EMEP & Highly time resolved measurements of inorganic gases and aerosols & $2006-2008$ \\
\hline GOP & Quantitative precipitation forecasting & 2007 \\
\hline EUCAARI-IMPACT & Cloud aerosol interaction & 2008 \\
\hline ESA-CALIPSO & $\begin{array}{l}\text { NASA/CNES cloud aerosol lidar with orthogonal polarisation } \\
\text { (CALIOP) correlative measurements }\end{array}$ & 2009 \\
\hline CINDI & Cabauw Intercomparison of Nitrogen Dioxide measuring Instruments & 2009 \\
\hline CLIC & Cabauw Lightmeter Intercomparison & 2012 \\
\hline PEGASOS & Pan-European Gas-Aerosols-Climate interaction Study & 2012 \\
\hline INGOS & CH4 flux intercomparison campaign & 2012 \\
\hline $\mathrm{HD}(\mathrm{CP}) 2$ & $\begin{array}{l}\text { High Definition Clouds and Precipitation for advancing Climate } \\
\text { Predictions }\end{array}$ & 2013 \\
\hline ACCEPT & $\begin{array}{l}\text { Analysis of the Composition of mixed-phase Clouds with Extended } \\
\text { Polarization Techniques }\end{array}$ & 2014 \\
\hline CINDI-2 & $\begin{array}{l}\text { Cabauw Intercomparison of Nitrogen Dioxide Measuring } \\
\text { Instruments }\end{array}$ & 2016 \\
\hline PICAB & $\begin{array}{l}\text { Proton-transfer-reaction mass spectrometer (PTR-MS) } \\
\text { Intercomparison campaign in Cabauw }\end{array}$ & 2017 \\
\hline TROLIX & TROPOMI validation campaign & 2019 \\
\hline
\end{tabular}

on aviation over the European continent. In other cases it may take a decade from making the observations, using them in model evaluation, improving the model, and application of the model in the weather service for improved weather forecasts. As shown in Sect. 4.2.3 the recent improvements in the new version of the ECMWF model were, amongst others, based on tower observations from Lindenberg, Hamburg, and Cabauw from 7 years earlier (Sandu et al. 2013a).

As another factor that contributes to the success of Cabauw we mention the open data policy. Already from the beginning of the measurement program data have been disseminated throughout the international research community, in the early years in print, later on floppy disks, and nowadays through the internet (www.cesar-database.nl). This has facilitated 


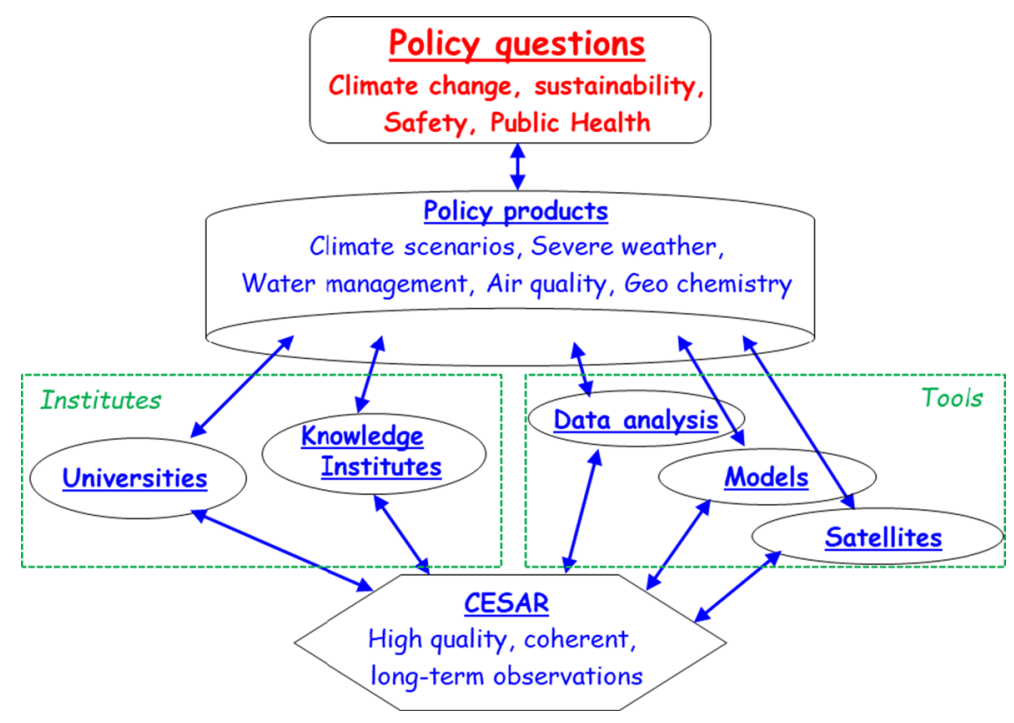

Fig. 11 The layered structure linking CESAR observations to policy oriented products

researchers around the world to freely test their scientific ideas and their model representations over the last 50 years, and hopefully continues to do so for the next decades.

The new Ruisdael project offers the possibility to integrate all atmospheric research and observations in the Netherlands. In particular the KNMI testbed will be expanded to offer new possibilities to integrate fine-scale modelling and observations and in which Cabauw plays a key role.

Cabauw will continue to acquaint new generations of fundamental and applied scientists with the relevance of land-atmosphere interactions for studies of weather, climate and air quality. The courses on boundary-layer processes at the University of Utrecht, Wageningen University and TU-Delft include yearly visits to the site facility. The free online software CLASS (http://classmodel.github.io/) (Vilà-Guerau de Arellano et al. 2015) is based on mixed-layer theory developed on early Cabauw data (Tennekes and Driedonks 1981). It has as a default case with prescribed surface and boundary-layer characteristics of Cabauw.

Acknowledgement The authors thank Cindy Werner, funded by the U.S. National Science Foundation International Research Fellowship program (Grant \# INT-0202636), who initiated the regional-scale flux program at Cabauw. Thanks to Frank Beyrich of the Meteorological Observatory Lindenberg, Germany and Young-San Park of the Boseong facility in South Korea for providing information on tall towers. Also thanks to generations of colleagues for their support in maintaining Cabauw at the technical, scientific, and organisational levels. In particular Herman Russchenberg, Andre van Lammeren, and Arnoud Apituley for their support in founding and continuing the CESAR consortium. One of the founders of Cabauw, Jon Wieringa, recently passed away. At the start of Cabauw he played an essential role in the design of the meteorological tower and in the set-up of the wind observations, the principles of which are still used today.

Open Access This article is licensed under a Creative Commons Attribution 4.0 International License, which permits use, sharing, adaptation, distribution and reproduction in any medium or format, as long as you give appropriate credit to the original author(s) and the source, provide a link to the Creative Commons licence, and indicate if changes were made. The images or other third party material in this article are included in the article's Creative Commons licence, unless indicated otherwise in a credit line to the material. If material is not included in the article's Creative Commons licence and your intended use is not permitted by statutory 
regulation or exceeds the permitted use, you will need to obtain permission directly from the copyright holder. To view a copy of this licence, visit http://creativecommons.org/licenses/by/4.0/.

\section{References}

Andreae MO et al (2015) The Amazon Tall Tower Observatory (ATTO): overview of pilot measurements on ecosystem ecology, meteorology, trace gases, and aerosols. Atmos Chem Phys 15:10723-10776

Angevine WM, Klein Baltink H, Bosveld FC (2001) Observations of the morning transition of the convective boundary layer. Boundary Layer Meteorol 101:209-227

Arrillaga JA, Vilà-Guerau de Arellano J, Bosveld F, Klein Baltink H, Yagüe C, Sastre M, Román-Cascón C (2018) Impacts of afternoon and evening sea-breeze fronts on local turbulence, and on $\mathrm{CO}_{2}$ and radon-222 transport. Q J R Meteorol Soc 144:990-1011

Baas P, Bosveld FC, Klein Baltink H, Holtslag AAM (2009) A climatology of nocturnal low-level jets at Cabauw. J Appl Meteorol Climatol 48:1627-1642

Baas P, Bosveld FC, Lenderink G, van Meijgaard E, Holtslag AAM (2010) How to design single-column model experiments for comparison with observed nocturnal low-level jets? Q J R Meteorol Soc 136:671-684

Baas P, van de Wiel BJH, van den Brink L, Holtslag AAM (2012) Composite hodographs and inertial oscillations in the nocturnal boundary layer. Q J R Meteorol Soc 138:528-535

Baas P, Bosveld FC, Burgers G (2016) The impact of atmospheric stability on the near-surface wind over sea in storm conditions. Wind Energy 19:187-198

Basu S (2018) A simple recipe for estimating atmospheric stability solely based on surface-layer wind speed profile. Wind Energy 21:937-941

Beljaars ACM, Bosveld FC (1997) Cabauw data for the validation of land surface parameterization schemes. J Clim 10:1172-1193

Beljaars ACM, Holtslag AAM (1991) Flux parameterization over land surfaces for atmospheric models. J Appl Meteorol 30:327-341

Beljaars ACM, Schotanus P, Nieuwstadt FTM (1983) Surface layer similarity under nonuniform fetch conditions. J Clim Appl Meteorol 22:1800-1810

Bengtsson L, Andrae U, Aspelien T, Batrak Y, Calvo J, De Rooy W, Gleeson E, Hansen-Sass B, Homleid M, Hortal M, Ivarsson K-I, Lenderink G, Niemelä S, Pagh Nielsen K, Onvlee J, Rontu L, Samuelsson P, Santos Muñoz D, Subias A, Tijm S, Toll V, Yang X, Ødegaard Køltzow M (2017) The HARMONIE-AROME model configuration in the ALADIN-HIRLAM NWP system. Mon Weather Rev 145:1919-1935

Bergot T, Carrer D, Noilhan J, Bougeault P (2005) Improved site-specific numerical prediction of fog and low clouds: a feasibility study. Weather Forecast 20:627-646

Beyrich F, Mengelkamp H-T (2006) Evaporation over a heterogeneous land surface: EVA_GRIPS and the LITFASS-2003 experiment-an overview. Boundary-Layer Meteorol 121:5-32

Blackadar AK (1957) Boundary layer wind maxima and their significance for the growth of nocturnal inversions. Bull Am Meteorol Soc 38(5):283-290

Boers R, Klein Baltink H, Hemink HJ, Bosveld FC, Moerman M (2013) Ground-based observations and modeling of the visibility and radar reflectivity in a radiation fog layer. J Atmos Ocean Technol 30:288-300

Boers R, van Weele M, van Meijgaard E, Savenije M, Siebesma AP, Bosveld F, Stammes P (2015) Observations and projections of visibility and aerosol optical thickness (1956-2100) in the Netherlands: impacts of time-varying aerosol composition and hygroscopicity. Environ Res Lett 10:015003

Bosveld FC (2020) The Cabauw in situ observational program from 2000-present: instruments, calibrations and set-up. KNMI Technical report TR-384. De Bilt, The Netherlands. http://bibliotheek.knmi.nl/ knmipubTR/TR384.pdf. Accessed 15 July 2020

Bosveld FC, Beljaars ACM, Van Ulden AP (1999) A comparison of ECMWF Re-Analysis data with fluxes and profiles observed in Cabauw. ECMWF Re-Analysis Project Report Series No. 8

Bosveld FC, Baas P, vanMeijgaard E, de Bruijn EIF, Steeneveld G-J, Holtslag AAM (2014a) The third GABLS intercomparison case for evaluation studies of boundary layer models: Part A: case selection and set-up. Boundary-Layer Meteorol 152:133-156

Bosveld FC, Baas P, Steeneveld G-J, Holtslag AAM, Angevine WM, Bazile E, de Bruijn EIF, Deacu D, Edwards JM, Ek M, Larson VE, Malardel S, Pleim JE, Raschendorfer M, Svensson G (2014b) The third GABLS intercomparison case for boundary layer model evaluation. Part B: results and process understanding. Boundary-Layer Meteorol 152:157-187

Braam M, Bosveld FC, Moene AF (2012) On Monin-Obukhov (2012) scaling in and above the atmospheric surface layer: the complexities of elevated scintillometer measurements. Boundary-Layer Meteorol 144:157-177 
Brauer CC, Torfs PJJF, Teuling AJ, Uijlenhoet R (2014) The Wageningen Lowland Runoff Simulator (WALRUS): application to the Hupsel Brook catchment and the Cabauw polder. Hydrol Earth Syst Sci 18:4007-4028

Brümmer B, Lange I, Konow H (2012) Atmospheric boundary layer measurements at the $280 \mathrm{~m}$ high Hamburg weather mast 1995-2011: mean annual and diurnal cycles. Meteorol Zeit 21(4):319-335

Casso-Torralba P, Vilà-Guerau de Arellano J, Bosveld F, Soler MR, Vermeulen A, Werner C, Moors E (2008) Diurnal and vertical variability of the sensible heat and carbon dioxide budgets in the atmospheric surface layer. J Geophys Res 113:D12119

Chang S, Hahn D, Yang C-H, Norquist D, Ek M (1999) Evaluation study of the CAPS model landsurface scheme using the Cabauw/PILPS dataset. J Appl Meteorol 38(4):405-422

Chen TH et al (1997) Cabauw experimental results from the Project for Intercomparison of Landsurface Parametrization Schemes (PILPS). J Clim 10:1194-1215

Cuxart J, Tatrai D, Weidinger T, Kircsi A, Józsa J, Kiss M (2016) Infrasound as a detector of local and remote turbulence. Boundary-Layer Meteorol 159:185-192

De Bruin HAR, Holtslag AAM (1982) A simple parameterization of the surface fluxes of sensible and latent heat during daytime compared with the Penman-Monteith concept. J Appl Meteorol 21:1610-1620

De Bruin HAR, Lablans WN (1987) Reference crop evapotranspiration determined with a modified Makkink equation. Hydrol Proc 12(7):1053-1062

De Bruin HAR, Trigo IF, Bosveld FC, Meirink JF (2016) A thermodynamically based model for actual evapotranspiration of an extensive grass field close to FAO reference, suitable for remote sensing application. J Hydrometeorol 17:1373-1382

De Roode S, Bosveld FC, Kroon PS (2010) Dew formation, eddy-correlation latent heat fluxes, and the surface energy imbalance at Cabauw during stable conditions. Boundary-Layer Meteorol 135:369-383

Donda JMM, Van de Wiel BJM, Bosveld FC, Beyrich F, van Heijst GJF, Clercx HJH (2013) Predicting nocturnalwind and temperature profiles based on external forcing parameters. Boundary-Layer Meteorol 146:103-117

Donovan DP, Apituley A (2013) Practical depolarization-ratio based inversion procedure: lidar measurements of the Eyjafjallajökull ash cloud over the Netherlands. Appl Opt 52:2394-2415

Driemel A, Augustine J, Behrens K, Colle S, Cox C, Cuevas-Agulló E, Denn FM, Duprat T, Fukuda M, Grobe H, Haeffelin M, Hyett N, Ijima O, Kallis A, Knap W, Kustov V, Long CN, Longenecker D, Lupi A, Maturilli M, Mimouni M, Ntsangwane L, Ogihara H, Olano X, Olefs M, Omori M, Passamani L, Bueno Pereira E, Schmithüsen H, Schumacher S, Sieger R, Tamlyn J, Vogt R, Vuilleumier L, Xia X, Ohmura A, König-Langlo G (2018) Baseline Surface Radiation Network (BSRN): structure and data description (1992-2017). Earth Syst Sci Data 10:1491-1501

Duynkerke PG (1991a) Radiation fog: a comparison of model simulation with detailed observations. Mon Wea Rev 119:324-341

Duynkerke PG (1991b) Observation of a quasi-periodic oscillation due to gravity waves in a shallow radiation fog. Q J R Meteorol Soc 117:1207-1224

Duynkerke PG (1999) Turbulence, radiation and fog in Dutch stable boundary layers. Boundary-Layer Meteorol 90:447-477

Foken T (2008) The energy balance closure problem-an overview. Ecol Appl 18(6):1351-1367

Fuertes FC, Iungo GV, Porté-Agel F (2014) 3D turbulence measurements using three synchronous wind lidars: validation against sonic anemometry. J Atmos Oceanic Techn 31:1549-1556

Gryning SE, Batchvarova E, Brümmer B, Jørgensen H, Søren Larsen S (2007) On the extension of the wind profile over homogeneous terrain beyond the surface boundary layer. Boundary-Layer Meteorol 124:251-268

Gustafson WI, Vogelmann AM, Cheng X, Dumas KK, Endo S, Johnson KL, Krishna B, Li Z, Toto T, Xiao H (2019) Description of the LASSO Data Bundles Product. DOE Atmospheric Radiation Measurement (ARM) user facility. DOE/SC-ARM-TR-216. https://doi.org/10.2172/1469590

Halldin S, Lindroth A (1992) Errors in net radiometry. Comparison and evaluation of six radiometer designs. J Atmos Ocean Technol 9(6):762-783

Henderson-Sellers A, Pitman AJ, Love PK, Irannejad P, Chen TH (1995) The Project for Intercomparison of Land Surface Parameterization Schemes (PILPS): phase 2 and 3. Bull Am Meteorol Soc 76(4):489-503

Heus T, van Heerwaarden CC, Jonker HJJ, Siebesma APP, Axelsen S, van den Dries K, Geoffroy O, Moene AF, Pino D, de Roode SR, Vilà-Guerau de Arellano J (2010) Formulation of the Dutch Atmospheric Large-Eddy Simulation (DALES) and overview of its applications. Geosci Model Dev 3:415-444

Holtslag AAM (1984) Estimates of diabatic wind speed profiles from near surface weather observations. Boundary-Layer Meteorol 29:225-250

Holtslag AAM, de Bruin HAR (1988) Applied modeling of the nighttime surface energy balance over land. J Appl Meteorol 27:689-704 
Holtslag AAM, Duynkerke PG (eds.) (1998) Clear and cloudy boundary layers. In: Proceedings of the colloquium 'Clear and cloudy boudary layers'. Royal Netherlands Academy of Arts and Sciences, P.O. Box 19121, 100 GC Amsterdam, The Netherlands. ISBN 90-6984-235-1, 372 pp

Holtslag AAM, van Ulden AP (1983) A simple scheme for daytime estimates of the surface fluxes from routine weather data. J Clim Appl Meteorol 22:517-529

Holtslag AAM, Svensson G, Baas P, Basu S, Beare B, Beljaars ACM, Bosveld FC, Cuxart J, Lindvall J, Steeneveld GJ, Tjernstrom M, van de Wiel BJH (2013) Stable atmospheric boundary layers and diurnal Cycles-Challenges for Weather and Climate Models. Bull Am Meteorol Soc 94:1691-1706

Horiguchi M, Hayashi T, Adachi A, Onogi S (2012) Large-Scale turbulence structures and their contributions to the momentum flux and turbulence in the near-neutral atmospheric boundary layer observed from a 213-m tall meteorological tower. Boundary-Layer Meteorol 144:179-198

Izett JG, Schilperoord B, Coenders-Gerrits M, Baas P, Bosveld FC, van de Wiel BJH (2019) Missed fog? On the potential of obtaining observations at increased resolution during shallow fog events. Boundary-Layer Meteorol 173:289-309

Jacobs AFG, Heusinkveld BG, Holtslag AAM (2007) Seasonal and interannual variability of carbon dioxide and water balances of a grassland. Clim Change 82:163-177

Jacobs AFG, Heusinkveld BG, Holtslag AAM (2010) Eighty years of meteorological observations at Wageningen, the Neterlands: precipitation and evaporation. Int J Climatol 30(9):1315-1321

Jiménez PA, Vila-Guerau Jordi, de Arellano J, Dudhia J, Bosveld FC (2016) Role of synoptic- and mesoscales on the evolution of the boundary-layer wind profile over a coastal region: the near-coast diurnal acceleration. Meteorol Atmos Phys 128:39-56

Kangas M, Rontu L, Fortelius C, Aurela M, Poikonen A (2016) Weather model verification using Sodankylä mast measurements. Geosci Instrum Method Data Syst 5:75-84

Klein Baltink H(1998) A long-term intercomparison of windprofiler/RASS and tower measurements. Meteorol Zeit 7:271-279

Knoop S, Ramakrishnan P, Wijnant IL (2019) DOWA validation against Cabauw meteomast wind measurements. KNMI Technical report; TR-375, De Bilt, The Netherlands. http://bibliotheek.knmi.nl/ knmipubTR/TR375.pdf. Accessed 15 July 2020

Kohler M, Metzger J, Kalthoff N (2018) Trends in temperature and wind speed from 40 years of observations at a 200-m high meteorological tower in Southwest Germany. Int J Climatol 38:23-34

Kohsiek W, Meijninger WML, Moene AF, Heusinkveld BG, Hartogensis OK, Hillen WCAM, de Bruin HAR (2002) An extra large aperture scintellometer (XLAS) with a $9.8 \mathrm{~km}$ path length. Boundary Layer Meteorol 105:119-127

Kohsiek W, Liebethal C, Foken T, Vogt R, Oncley SP, Bernhofer C, De Bruin HAR (2007) The energy balance experiment EBEX-2000, Part III: behaviour and quality of the radiation measurements. Boundary Layer Meteorol 123:55-75

Lee X, Massman W, Law B (2004) Handbook of micrometeorology—a guide for surface flux measurement and analysis, vol 29. Atmospheric and Oceanographic Science Library. Kluwer Academic Publishers, Berlin

Lundin LC, Halldin S, Lindroth A, Cienciala E, Grelle A, Hjelm P, Kellner E, Lundberg A, Mölder M, Morén A-S, Nord T, Seibert J, Stähli M (1999) Continuous long-term measurements of soil-plant-atmosphere variables at a forest site. Agric Forest Meteorol 98-99:53-73

Maronga B, Bosveld FC (2017) Key parameters for the life cycle of nocturnal radiation fog: a comprehensive large-eddy simulation study. Q J R Meteorol Soc 143:2463-2480

Monahan AH, He Y, McFarlane N, Dai A (2012) The probability distribution of land surface wind speeds. J Clim 24:3892-3909

Monna W, Bosveld FC (2012) In higher spheres - 40 years of observations at the Cabauw Site. KNMI Publication 232, De Bilt, The Netherlands. http://bibliotheek.knmi.nl/knmipubmetnummer/knmipub232.pdf. Accessed 15 July 2020

Munn RE (1970) Editor's preface. Boundary-Layer Meteorol 1:3-4

Neggers RAJ, Siebesma AP, Heus T (2012) Continuous single-column model evaluation at a permanent meteorological supersite. Bull Am Meteorol Soc 93(9):1389-1400

Neisser J, Adam W, Beyrich F, Leiterer U, Steinhagen H (2002) Atmospheric boundary layer monitoring at the Meteorological Observatory Lindenberg as a part of the "Lindenberg Column": facilities and selected results. Meteorol Zeit 11(4):241-253

Optis M, Monahan A, Bosveld FC (2014) Moving beyond Monin-Obukhov similarity theory in modelling wind-speed profiles in the lower atmospheric boundary layer under stable stratification. Boundary-Layer Meteorol 153:497-514

Predrag P, Romanic D, Curic M (2018) Homogeneity analysis of wind data from $213 \mathrm{~m}$ high Cabauw tower. Int J Climatol 38:e1076-e1090 
Qing-Yao X, Fei H, Xue-Ling C (2017) Temperature oscillations observed in the stable boundary layer over four different underlying surfaces. Atmos Ocean Sci Lett 10(3):243-251

Rijkoort PJ (1961) Windspeed profiles measured along masts for Radio Nederland and television. KNMI Report V-100, De Bilt, The Netherlands (in Dutch)

Rijkoort PJ, Schmidt FH, Velds CA, Wieringa J (1970) A meteorological 80-m tower near Rotterdam. Boundary-Layer Meteorol 1:5-17

Sandu I, Beljaars A, Balsamo G (2013a) Improving the representation of stable boundary layers. ECMWF Newsletter No. 138, 24-29, Reading, UK

Sandu I, Beljaars A, Bechtold P, Mauritsen T, Balsamo G (2013b) Why is it so difficult to represent stably stratified conditions in numerical weather prediction (NWP) models? J Adv Mod Earth Sys 5:117-133

Schalkwijk J, Jonker H, Siebesma A, Bosveld FC (2015) A year-long large-eddy simulation of the weather over Cabauw: an overview. Mon Wea Rev 143:828-844

Schulz JP, Dumenil L, Polcher J, Schlosser CA, Xue Y (1998) Land surface energy and moisture fluxes: comparing three models. J Appl Meteorol 37:288-307

Sikma M, Vilà-Guerau de Arellano J, Pedruzo-Bagazgoitia X, Voskamp T, Heusinkveld BG, Anten NPR, Evers JB (2019) Impact of future warming and enhanced $\left[\mathrm{CO}_{2}\right]$ on the vegetation-cloud interaction. J Geophys Res Atmos 124:12444-12454

Sisterson DL, Peppler RA, Cress TS, Lamb PJ, Turner DD (2016) The ARM southern great plains (SGP) site. AMS Meteorological Monographs 57:6.1-6.14

Smink MME, Assink J, Bosveld F, Smets P, Evers L (2019) A three-dimensional array for the study of infrasound propagation through the atmospheric boundary layer. J Geophys Res Atmos 124:9299-9313

Steele CJ, Dorling SR, von Glasow R, Bacon J (2014) Modelling sea-breeze climatologies and interactions on coasts in the southern North Sea: implications for offshore wind energy. Q J R Meteorol Soc 141:1821-1835

Su Z et al (2009) EAGLE 2006-multi-purpose, multi-angle and multi-sensor in situ and airborne campaigns over grassland and forest. Hydrol Earth Syst Sci 13:833-845

Super I, Vilà-Guerau de Arellano J, Krol MC (2015) Cumulative ozone effect on canopy stomatal resistance and the impact on boundary layer dynamics and $\mathrm{CO}_{2}$ assimilation at the diurnal scale: a case study for grassland in the Netherlands. J Geophys Res Biogeosci 120:1348-1365

Svensson G, Holtslag AAM (2009) Modeling the turning of wind and the related momentum fluxes in the stable boundary layer. Boundary-Layer Meteorol 132:261-277

Tennekes H, Driedonks AGM (1981) Basic entrainment equations for the atmospheric boundary layer. Boundary-Layer Meteorol 20:515-531

Teuling A et al (2010) Contrasting response of European forest and grassland energy exchange to heatwaves. Nat Geosci 3:722-727

Tijm ABC, Holtslag AAM, van Delden AJ (1999) Observations and modelling of the sea breeze with the return current. Mon Wea Rev 127:625-640

Trigo IF, De Bruin HAR, Beyrich F, Bosveld FC, Gavilán P, Groh J, López-Urreai R (2018) Validation of reference evapotranspiration from Meteosat Second Generation (MSG) observations. Agric Forest Meteorol 259:271-285

Van de Wiel BJH, Moene AF, Steeneveld GJ, Baas P, Bosveld FC, Holtslag AAM (2010) A conceptual view on inertial oscillations and nocturnal low-level jets. J Atmos Sci 67:2679-2689

Van der Linden SJA, Baas P, Van Hooft JA, Van Hooijdonk IGS, Bosveld FC, Van de Wiel BJH (2017) Local characteristics of the nocturnal boundary layer in response to external pressure forcing. J Appl Meteorol Clim 56:3035-3047

Van der Schrier D, Van Ulden A, Van Oldenborgh GJ (2011) The construction of a Central Netherlands temperature. Clim Past 7:527-542

Van Heerwaarden CC, Vilà-Guerau de Arellano J, Gounou A, Guichard F, Couvreux F (2010) Understanding the daily cycle of evapotranspiration: a method to quantify the influence of forcings and feedbacks. J Hydrol 11(6):1405-1422

Van Hooijdonk IGS, Donda JMM, Clercx HJH, Bosveld FC, van de Wiel BJH (2015) Shear capacity as prognostic for nocturnal boundary layer regimes. J Atmos Sci 72(4):1518-1532

Van Ulden AP, Holtslag AAM (1985) Estimation of atmospheric boundary layer parameters for diffusion applications. J Clim Appl Meteorol 24:1196-1207

Van Ulden AP, Wieringa J (1996) Atmospheric boundary layer research at Cabauw. Boundary-Layer Meteorol 78:39-69

Vasiljević N, Lea G, Courtney M, Cariou JP, Mann J, Mikkelsen T (2016) Long-range windscanner system. Remote Sens 8(11):896-919

Verkaik JW, Holtslag AAM (2007) Wind profiles, momentum fluxes and roughness lengths at Cabauw revisited. Boundary-Layer Meteorol 122:701-719 
Vermeulen AT, Hensen A, Popa ME, Van den Bulk WCM, Jongejan PAC (2011) Greenhouse gas observations from Cabauw Tall Tower (1992-2010). Atmos Meas Tech 4:617-644

Viana S, Yague C, Maqueda G (2012) Vertical structure of the stable boundary layer detected by RASS-SODAR and in-situ measurements in SABLES 2006 field campaign. Acta Geophys 60:1261-1286

Vila-Guerau de Arellano J, Beniamino Gioli B, Miglietta F, Jonker HJJ, Klein Baltink H, Hutjes RWA, Holtslag AAM (2004) Entrainment process of carbon dioxide in the atmosphericboundary layer. J Geophys Res 109:D18110

Vilà-Guerau de Arellano J, van Heerwaarden C, Lelieveld J (2012) Modelled suppression of boundary-layer clouds by plants in a $\mathrm{CO}_{2}$-rich atmosphere. Nat Geosci 5:701-704

Vilà-Guerau de Arellano J, van Heerwaarden CC, van Stratum BJHM, van den Dries K (2015) Atmospheric boundary layer: integrating atmospheric chemistry and land interactions. Cambridge University Press, Cambridge

Wang P, Knap WH, Kuipers Munneke P, Stammes P (2009) Clear-sky shortwave radiative closure for the Cabauw Baseline Surface Radiation Network site, the Netherlands. J Geophys Res 114:D14206

Wessels HRA (1979) Growth and disappearance of evaporation fog during the transformation of a cold air mass. Q J R Meteorol Soc 105:963-977

Wessels HRA (1983) Distortion of the wind field by the Cabauw meteorological tower. KNMI scientific report 83-15, De Bilt, The Netherlands

Wessels HRA (1984) Cabauw meteorological data tapes 1973-984; Description of instrumentation and data processing for the continuous measurements. KNMI Scientific Report WR 84-6, De Bilt, The Netherlands

Wichink Kruijt RJ, Holtslag AAM, Tijm ABC (2004) Scaling of the sea-breeze strength with observations in the Netherlands. Boundary-Layer Meteorol 112:369-380

Wijnant IL, van Ulft B, van Stratum B, Barkmeijer J, Onvlee J, de Valk C, Knoop S, Kok S, Marseille GJ, Klein Baltink H, Stepek A (2019) The Dutch Offshore Wind Atlas (DOWA): description of the dataset. KNMI Technical report TR-380, De Bilt, The Netherlands

Winderlich J, Chen H, Gerbig C, Seifert T, Kolle O, Lavric JV, Kaiser C, Höfer A, Heimann M (2010) Continuous low maintenance $\mathrm{CO}_{2} / \mathrm{CH}_{4} / \mathrm{H}_{2} \mathrm{O}$ measurements at the Zotino Tall Tower Observatory (ZOTTO) in Central Siberia. Atmos Meas Tech 3:1113-1128

Wolfe DE, Lataitis RJ (2018) Boulder atmospheric observatory: 1977-2016: the end of an era and lessons learned. Bull Am Meteorol Soc 99:1345-1358

Publisher's Note Springer Nature remains neutral with regard to jurisdictional claims in published maps and institutional affiliations. 